Please do not remove this page

RMIT

UNIVERSITY

\title{
Determination of the transportable moisture limit of iron ore fines for the prevention of liquefaction in bulk carriers
}

Munro, Michael; Mohajerani, Abbas

https://researchrepository.rmit.edu.au/esploro/outputs/9921862353701341/filesAndLinks?institution=61RMIT_INST\&index=null

Munro, M., \& Mohajerani, A. (2015). Determination of the transportable moisture limit of iron ore fines for the prevention of liquefaction in bulk carriers. Marine Structures, 40(1), 193-224.

https://doi.org/10.1016/j.marstruc.2014.11.004

Document Version: Accepted Manuscript

Published Version: https://doi.org/10.1016/j.marstruc.2014.11.004

Repository homepage: https://researchrepository.rmit.edu.au

(c) 2014 Elsevier Ltd. All rights reserved.

Downloaded On 2023/04/26 15:50:01 +1000

Please do not remove this page 
Thank you for downloading this document from the RMIT Research Repository.

The RMIT Research Repository is an open access database showcasing the research outputs of RMIT University researchers.

RMIT Research Repository: http://researchbank.rmit.edu.au/

\section{Citatioon:}

Munro, M and Mohajerani, A 2015, 'Determination of the transportable moisture limit of iron ore fines for the prevention of liquefaction in bulk carriers', Marine Structures, vol. 40, no. 1, pp. 193-224.

See this record in the RMIT Research Repository at:

https://researchbank.rmit.edu.au/view/rmit:29221

Version: Accepted Manuscript

Copyright Statement: (c) 2014 Elsevier Ltd. All rights reserved.

Link to Published Version:

http://dx.doi.org/10.1016/j.marstruc.2014.11.004 


\title{
Determination of the Transportable Moisture Limit of Iron Ore Fines for the Prevention of Liquefaction in Bulk Carriers
}

\author{
Michael C. Munro a and Abbas Mohajerani ${ }^{\text {b }}$ \\ ${ }^{a}$ PhD Student, s3165374@student.rmit.edu.au \\ ${ }^{\text {b}}$ Senior Lecturer PhD, dr.abbas@rmit.edu.au \\ School of Civil, Environmental and Chemical Engineering, RMIT University, Melbourne, Victoria, Australia.
}

\begin{abstract}
In 2013, over 500 million metric tons of Iron Ore Fines (IOF) were transported around the world using bulk carriers. Under certain conditions IOF, while being transported, can possibly undergo liquefaction. Since 2006, there has been eight reported bulk carrier casualties possibly caused by the liquefaction of IOF. The objective of this study is to evaluate, compare and verify the limitations and relevance of the Proctor/Fagerberg, Flow Table and Penetration test methods that are used to determine the Transportable Moisture Limit (TML) of IOF. The TML is the maximum gross water content that bulk cargoes, including IOF, may contain while being transported at sea without being at risk of liquefying. A thorough literature review, along with laboratory research, was carried out to compare the TML results from the three leading test methods to determine whether they produce reliable results when testing IOF. The study concludes that the three test methods, as stated in the 2012 International Maritime Solid Bulk Cargoes Code, are unverified and therefore not appropriate for testing IOF. This is due to the variation in the results produced by the three test methods and also due to the difference in the physical properties of IOF when compared with the materials that were originally intended for testing. It is noted that the TML alone may not control the potential liquefaction of IOF and further studies, regarding the physical properties and system variables, which cause the material to liquefy, are required to determine the liquefaction potential of IOF.
\end{abstract}

Keywords - Bulk Cargoes, Fagerberg, Flow Table, Iron Ore Fines, Liquefaction, Transportable Moisture Limit.

$\begin{array}{lll}\text { Abbreviations - } & \text { BC Code } & \text { - Code of Safe Practice for Solid Bulk Cargoes [1] } \\ \text { CMC } & \text { - Critical Moisture Content } \\ \text { FMP } & \text { - Flow Moisture Point } \\ \text { FT } & \text { - Flow Table Test } \\ \text { IMSBC Code } & \text { - International Maritime Solid Bulk Cargoes Code [2] } \\ \text { IOF } & \text { - Iron Ore Fines } \\ \text { PF } & \text { - Proctor/Fagerberg Test } \\ \text { PT } & - \text { Penetration Test } \\ \text { TML } & - \text { Transportable Moisture Limit }\end{array}$

\section{Introduction}

In 2011, over 2.8 billion metric tons of iron ore was produced worldwide [3]. After its extraction, the iron ore is mechanically divided to produce three different qualities; fines $(<6.3 \mathrm{~mm})$, lump $(6.3-30 \mathrm{~mm})$ and pellets $(9.5-16 \mathrm{~mm})$ [4]. Since $98 \%$ of the iron ore produced is used to make steel, it is said to be "more integral to the global economy than any other commodity, except perhaps oil" [5]. Iron Ore Fines (IOF) make up approximately $48 \%$ of the iron ore trade, which in 2011, was approximately 1.3 billion metric tons [6].

In 2004, approximately 400 million metric tons of IOF were transported around the world using bulk carriers, with Australia and Brazil dominating the seaborne trade. The vessels used to transport IOF vary in size, with the largest being Capesize bulk carriers [7]. Unlike a tanker, where the cargo holds surface areas are minimized, bulk carriers store their cargo in large holds accessed by individual hatch covers. These holds are separated along the length and extend the full width of the vessel. This design is intended to transport solid granular materials.

Since the holds of bulk carriers are not designed to carry liquid, if liquefaction of IOF or other materials occur, while being transported, it can cause the vessel to list or even capsize. This is due to the material shifting from one side of the hold to the other and causing the vessel to become unbalanced. If a vessel begins to list, ballast is used to try to 
correct the problem. Due to the weight of iron ore, and similar materials, this can sometimes be very difficult to correct. If the vessel continues unbalanced the list can become more pronounced and the vessel can capsize. Since 2006, there has been eight reported bulk carrier casualties possibly caused by liquefaction of IOF [8-12]. Seen in Figure 1 and Figure 2 are two bulk carriers that were lost due to possible liquefaction of the cargo of IOF.

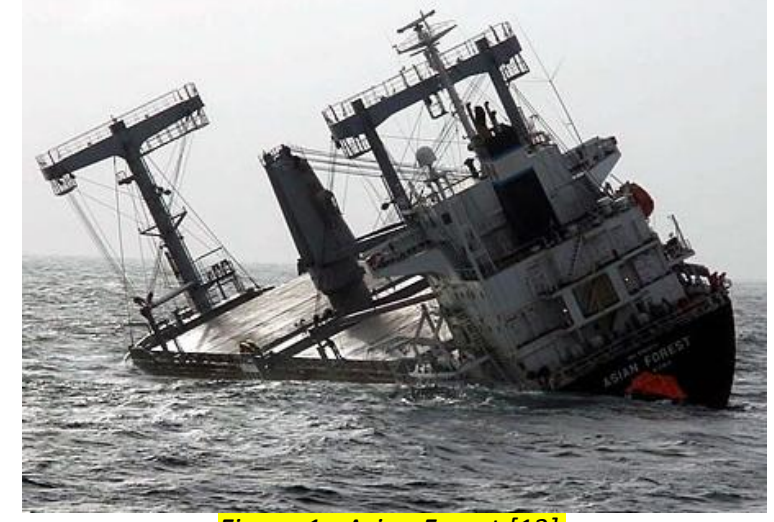

Figure 1 - Asian Forest [13].

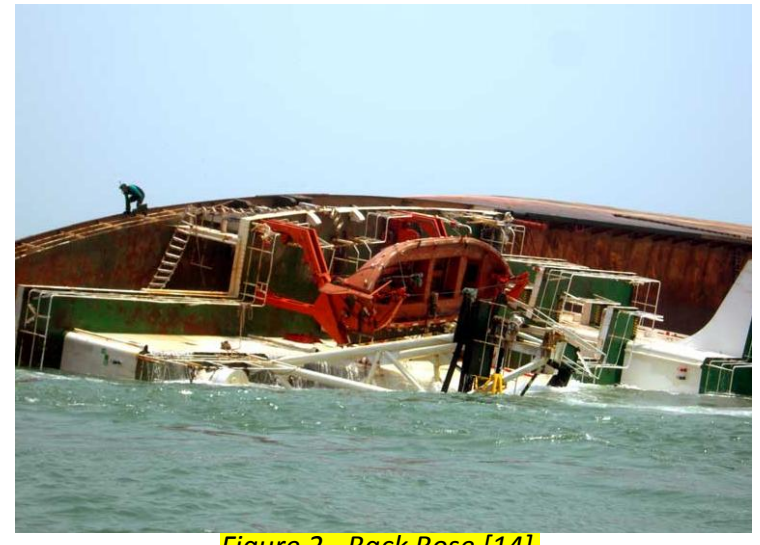

Figure 2 - Back Rose [14].

Although liquefaction has been known to cause vessels to capsize, since the loss of the Bengal in 1910 [15], up until 2011, owners have been able to apply the International Maritime Solid Bulk Cargoes Code, hereafter called the IMSBC Code [2], on a voluntary basis [16]. The IMSBC Code, formally the Code of Safe Practice for Solid Bulk Cargoes (BC Code) [1], is an internationally accepted code of safe practice created to address the problems involved in the transportation of bulk cargos, including IOF. In January 2011, the IMSBC Code became part of a mandatory requirement that is to be followed by all owners of vessels carrying solid bulk cargos [17].

The IMSBC Code outlines dangers associated with certain types of solid bulk cargos and provides procedures to be followed when transporting these materials. Included in the code are test methods used to determine the Transportable Moisture Limit (TML) of 'Group A' cargoes. 'Group A' cargoes are those that have the potential to liquefy due to the proportion of fine particles and moisture they contain. Before 2011, IOF were not specifically listed in the IMSBC Code [18]. The 2012 IMSBC Code now classifies IOF as a, 'Group A', liquefiable cargo.

The three test methods used to determine the TML of liquefiable materials were created, and incorporated, in the IMSBC code a considerable time before the addition of IOF to the list of liquefiable cargos within. Due to IOF now being a 'Group A' liquefiable cargo, they are now required to undergo TML testing using these predetermined and unmodified methods. The TML is the maximum gross water content that bulk cargoes, including IOF, may contain while being transported at sea without being at risk of liquefying. Additional information on terminology used in this study can be seen in Appendix A.

When determining the TML of a material, the IMSBC Code provides three test methods that can be used. They are the Flow Table test, Penetration test and Proctor/Fagerberg test. These three test methods are discussed in section 2 of this paper. Other tests that have been used to determine the TML of a material, but not mentioned in the IMSBC Code, are tests such as the vibrating platform method, developed by British Coal [19], a drainage method, produced by Norway [20], and a method using a concrete tester developed in Finland [15].

The main objective of this study is to evaluate, compare and determine the limitations and relevance of the three leading test methods used to determine the TML of IOF. This study will also deliver examples why the 2012 IMSBC Code, in regards to TML testing, can at sometimes be misleading when testing IOF.

\subsection{Liquefaction}

This section includes the basic principles of liquefaction and is included in this study to illustrate that the underlying factors why IOF potential to liquefy may be much more complex than initially perceived. Liquefaction is a description of the follow-on effect of a static or dynamic load being applied to a material, usually a fine sand or silt, resulting in the material acting like a liquid. "Liquefies" was first termed in 1920 when referring to the failure of the Calaveras Dam in 1918 [21]. Since then, there have been numerous studies done on the subject. Although the subject is 
particularly complex, there have been found to be two common types of liquefaction, they are static and dynamic liquefaction.

Static liquefaction occurs less regularly than dynamic liquefaction. It is caused by increasing the shear stress in a material, usually by applying a monotonic load, until such a point is reached that one point of the material liquefies and propagates rapidly, from that point, to produce total liquefaction of the material. This can be seen graphically in Figure 3. Static liquefaction most commonly occurs in undrained or saturated conditions.

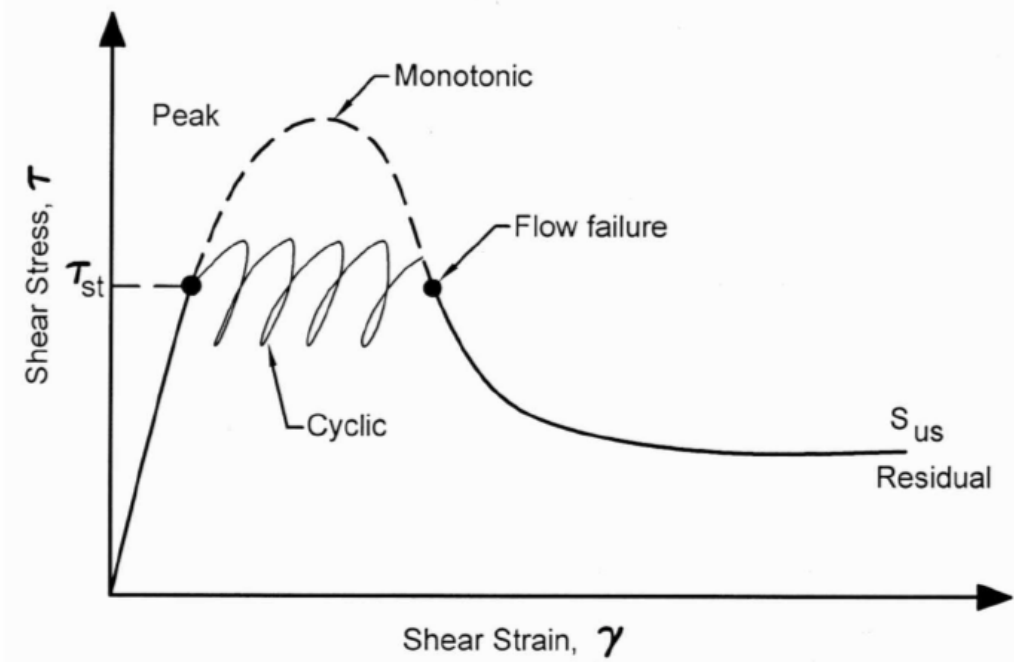

Figure 3 - Idealized response of saturated cohesionless tailings under monotonic and cyclic loading.

Dynamic liquefaction occurs more frequently than static liquefaction. This is because it is produced regularly by nature, in the form of earthquakes. Dynamic liquefaction occurs when a cyclic or dynamic load is applied to a material causing parameters within the material to change and therefore liquefy [22]. Dynamic liquefaction propagates throughout the material from a single point, like static liquefaction, to cause total liquefaction of the material. This phenomenon can occur in saturated or unsaturated materials.

Eq. 1 show the relationship between the effective stress $\left(\sigma^{\prime}\right)$, normal stress $(\sigma)$ and pore water pressure $\left(u_{w}\right)$ of a saturated material [23]. Referring to basic soil mechanics, the effective stress directly affects the resulting shear stress $(\tau)$, and eq. 1 show that increasing pore water pressure reduces the effective stress. The pore water pressure can be suddenly increased by applying dynamic energy or a monotonic load. If the effective stress of a cohesionless material is reduced to zero, the shear stress is also reduced to zero and the material has the potential to liquefy.

$\sigma^{\prime}=\sigma-u_{w}$

Likewise, in partially saturated cohesionless materials, when the effective stress is reduced to zero, the shear stress is also reduced to zero. The difference between the resulting effective stress of a saturated verses partially saturated material is the presence of pore air pressure $\left(u_{a}\right)$ and a factor of the degree of saturation $(X)$, as seen in eq. 2 [24].

$\sigma^{\prime}=\left(\sigma-u_{a}\right)+X\left(u_{a}-u_{w}\right)$

When static, the pore water pressure is negative and this suction force has a tendency to hold the particles together, as seen in Figure 4, but when a monotonic load or dynamic energy is applied the pore air pressure and pore water pressure will increase and force the particles apart, as seen in Figure 5. Since air compresses and water does not, the pores filled with air will reduce causing a decrease in the void ratio and an increase in the degree of saturation. Under certain conditions this can cause the effective stress of a material to reduce to zero causing the material to become potentially liquefiable. 


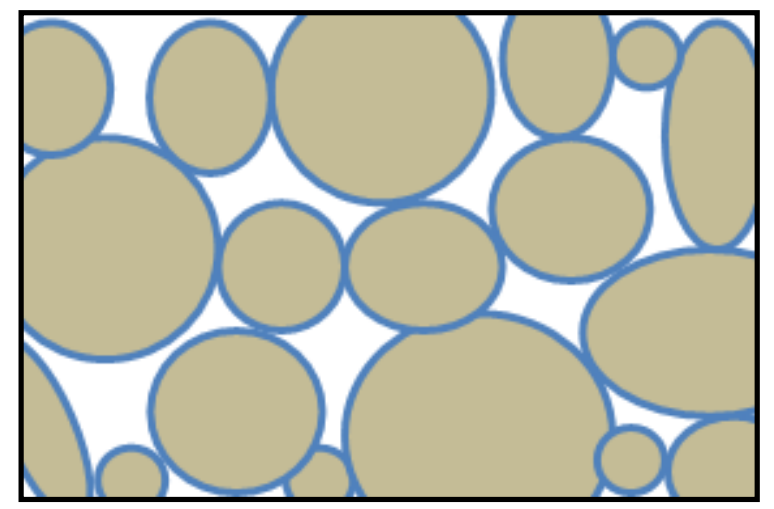

Figure 4-Wetted particles.

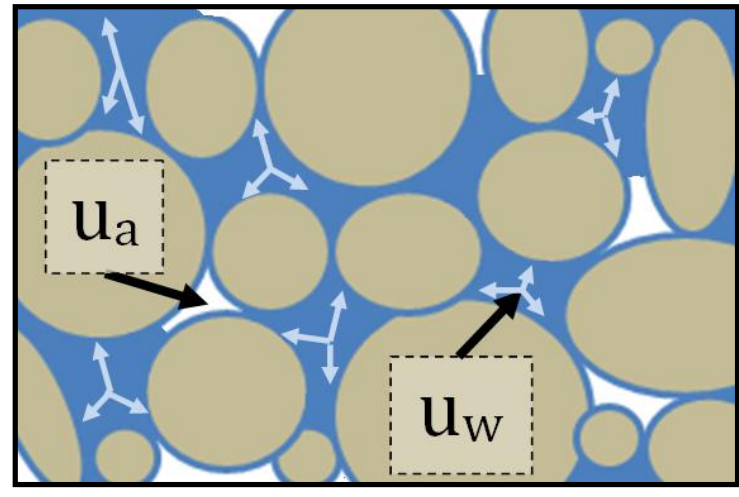

Figure 5-Partially saturated particles.

The complex behaviour IOF exhibit when it undergoes liquefaction is dissimilar from that of soils and tailings. As IOF are transported in bulk carriers, the energy transmitted from the waves and the vessels engine varies from the energy produced from more common causes of liquefaction, such as earthquakes. This input of energy consolidates the IOF, as it is being transported, reducing the void ratio of the material closer to the bottom of the hold as well as increasing its degree of saturation. The extraction, refining and storage of IOF contribute to the moisture that the material contains when it is loaded onto bulk carriers. IOF are commonly loaded as dry as possible, as seen in Figure 6 , but sometimes contain significant moisture, as seen in Figure 7. A combination of the moisture content, dynamic energy produced by the waves and the vessels engine along with the weight of the material itself leads us to believe that the material may be undergoing a combination of both static and dynamic liquefaction.

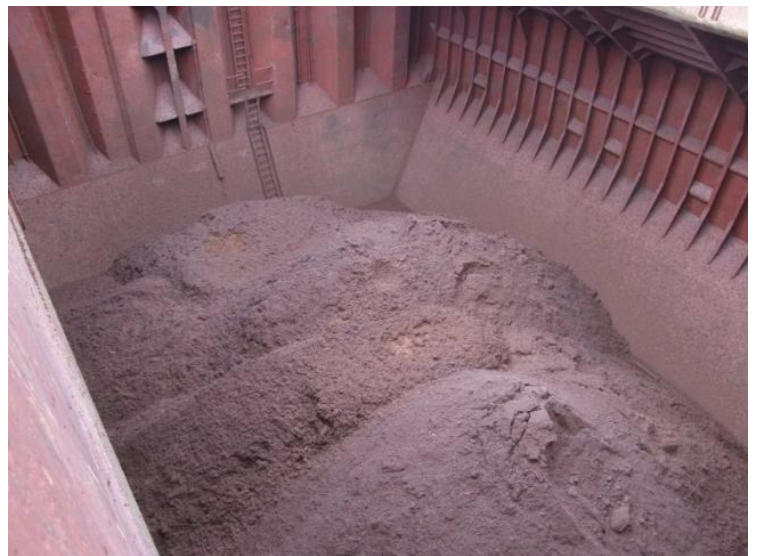

Figure 6 - Dry IOF being loaded onto a bulk carrier [25].

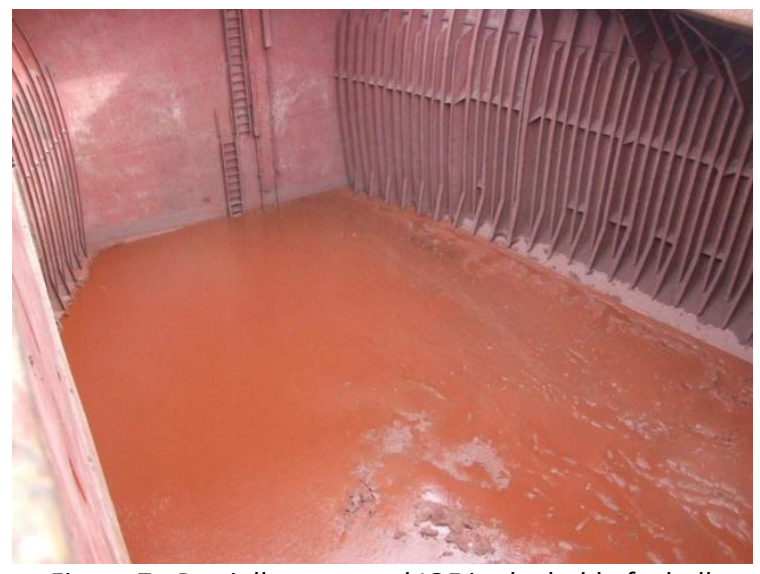

Figure 7 - Partially saturated IOF in the hold of a bulk carrier in India [25].

Although all IOF may not be potentially liquefiable, the risk that IOF pose, when being transported, is significant. Further studies need to be completed to determine what physical properties of IOF determine the resulting TML and if there are limits on the physical properties, which could indicate that a sample does not have the potential to liquefy.

\section{TML Test Procedures}

\subsection{Proctor/Fagerberg Test}

\subsubsection{Background}

The Proctor/Fagerberg test was first published in Stockholm in 1962 by Bengt Fagerberg and Kjell Eriksson as part of a committee established by the Swedish Mining Association and several Scandinavian mining companies. The committee was given the task to develop a simple method for determining the critical moisture content (CMC) of individual cargos [26]. The test method is based upon use of the Proctor apparatus developed in soil mechanics [27] and was adopted by the International Maritime Organization, for use in the BC Code [1], between 1991 and 1998. The critical moisture content in the Proctor/Fagerberg test is also known as the TML.

\subsubsection{Procedure}


The procedure to determine the TML of a material, according to the Proctor/Fagerberg test, begins by drying out enough material, at approximately $100^{\circ} \mathrm{C}$, to fill a one litre mould 5-10 times. Once dry, a suitable amount of water is added to the first test portion and mixed thoroughly for five minutes. The mould is then filled to approximately one fifth of the height, levelled off then the material is compacted uniformly with a compaction hammer. Compacting is executed by dropping a $350 \mathrm{~g}$ hammer, 25 times, though a guided pipe from a height of $0.2 \mathrm{~m}$. This procedure is repeated for all five layers. The compaction energy specified is from compaction "Method C" obtained by research carried out by Fagerberg and Stavang. More details on the compaction of the sample and energy can be seen in section 2.1.7.

After compaction is complete, the collar is removed and the sample is levelled along the brim with a straightedge, as seen in Figure 8. The weight of the mould and the sample is determined then the mould is emptied, as seen in Figure 9 , and the sample dried and weighed again. This procedure is then repeated at different moisture contents.

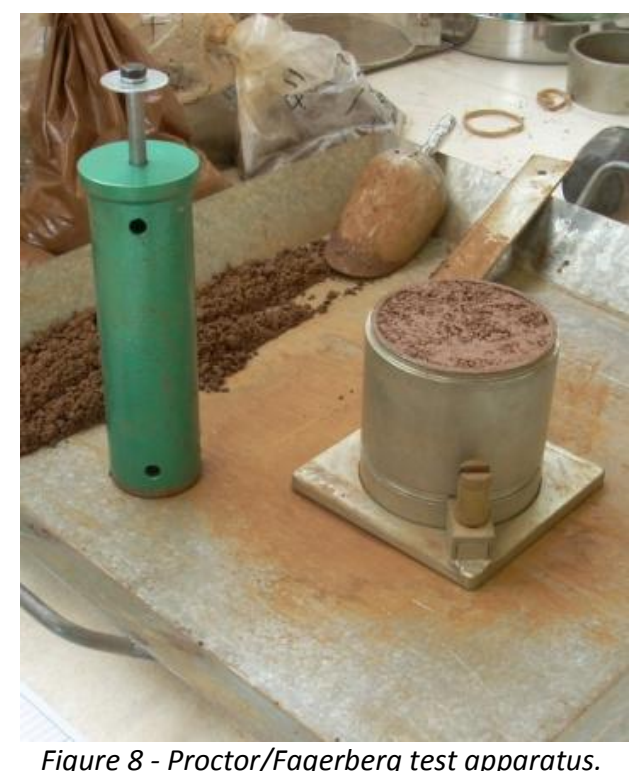

Figure 8 - Proctor/Fagerberg test apparatus.

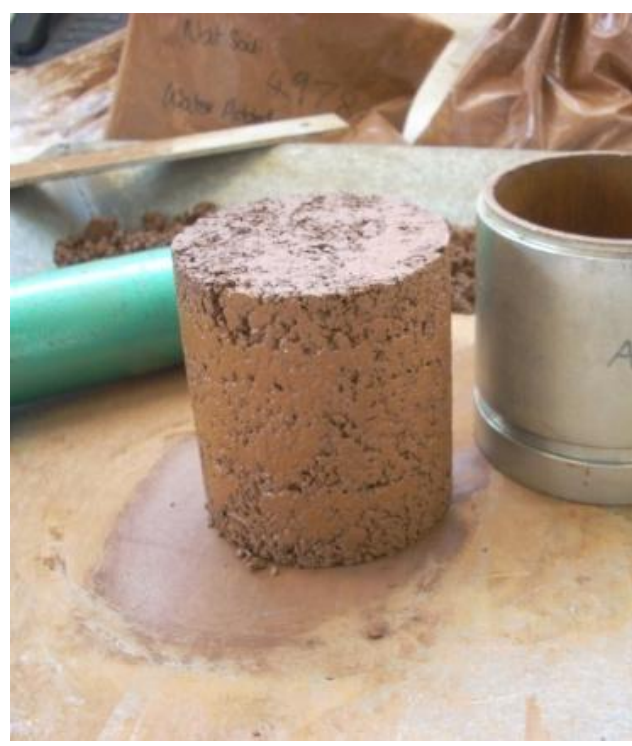

Figure 9 - Sample after compaction.

After 5-10 compactions at varying moisture contents have been performed and the gross water contents determined, standard soil mechanic equations are used to create a graphical representation of the samples compaction curve. A typical compaction curve, along with the resulting $T M L$, that is produced during a Proctor/Fagerberg test can be seen in Figure 10.

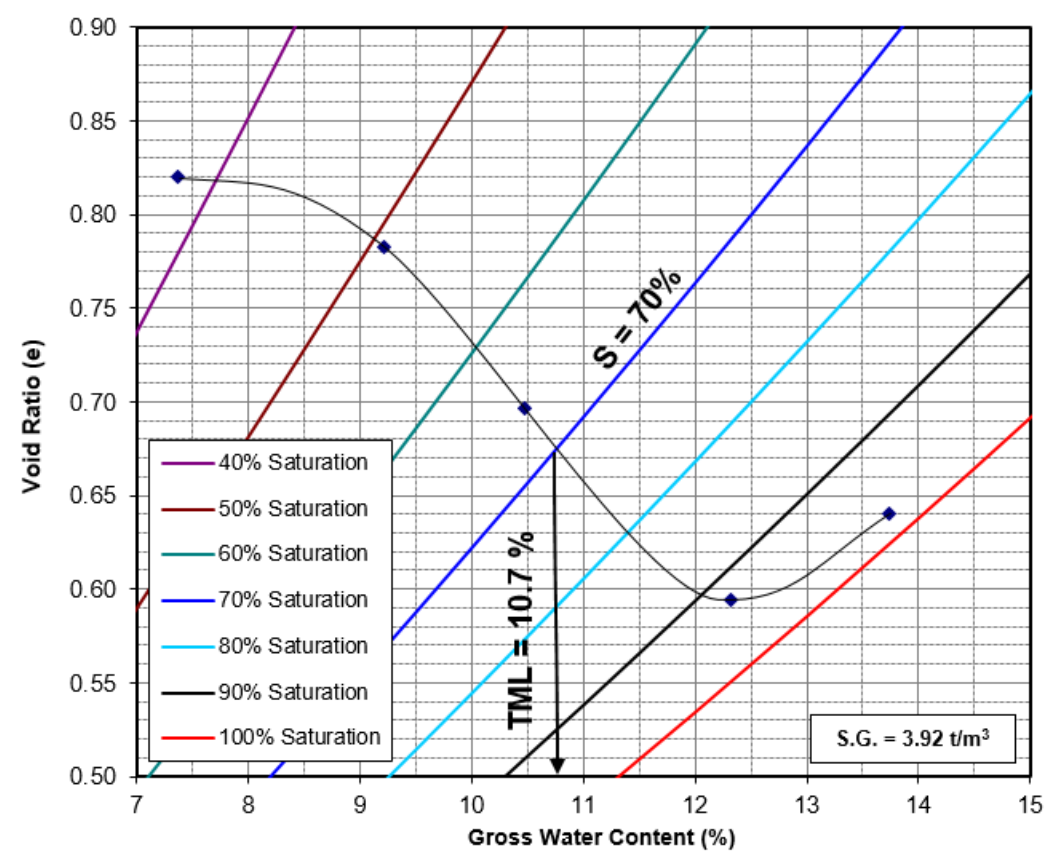

Figure 10 - Typical graphical representation of the compaction curve and resulting TML from the Proctor/Fagerberg test. 
The TML of the material is taken as equal to the gross water content when the material is $70 \%$ saturated. More details on why $70 \%$ saturation is used during this procedure can be seen in section 2.1.7. The calculations used for the Proctor/Fagerberg test can be seen in Appendix B.1 and typical IOF TML values for this test can be seen in Table C.1 in Appendix C.

The Proctor/Fagerberg test may require 20-40kg of IOF depending on how many compaction points are needed to complete the compaction curve. To complete the minimum of 5 points, covering the correct range of moisture contents, approximately $20 \mathrm{~kg}$ of material will be needed. The 2012 IMSBC Code states that the Proctor/Fagerberg test is only suitable for samples with a maximum particle size of $5 \mathrm{~mm}$.

\subsubsection{Estimated Test Time}

According to the procedure in the 2012 IMSBC Code, the Proctor/Fagerberg test can be completed in two days, one day for completing the compaction points, then the second to weigh the dry samples and create a graphical representation of the compaction curve. To calculate the saturation lines and void ratios needed for the graphical representation, the particle density must also be obtained. The determination of particle density can be completed, separately, in the same amount of time as the Proctor/Fagerberg test, therefore a sample can still be tested within two days although it will require additional labour. See section 2.1.6 for information regarding the determination of particle density for the Proctor/Fagerberg test.

\subsubsection{Reliability}

The Proctor/Fagerberg test uses set measurements to determine whether the TML has been reached and does not need the operator to interpret visually, or otherwise, the TML during the test. Since this test is based upon the widely used Proctor apparatus, developed in soil mechanics [27], it is easy for an operator familiar with the Proctor apparatus to perform the test. Compared with the Proctor compaction procedure, there are only slight differences in the compaction effort, number of layers and reporting requirements [2]. The Proctor/Fagerberg test has been widely accepted to have great repeatability and reproducibility when comparing against multiple operators and laboratories because of its similarity to the Proctor compaction procedure [27]. The preparation procedures are discussed in more detail in section 6 .

\subsubsection{Application of Materials}

Fagerberg and Stavang wrote in their 1971 paper, which is regarding the development of the Proctor/Fagerberg test, that the aim of the committee, appointed by the Swedish Mining Association, was to "develop a simple method for determining the critical moisture content of individual concentrates" [26]. There was no additional studies completed, up to the time the Proctor/Fagerberg test was introduced into the IMSBC Code, to determine if the test was valid for determining the TML of IOF.

\subsubsection{Particle Density (Specific Gravity)}

The importance of determining the particle density, of samples tested using the Proctor/Fagerberg method, is not emphasized in the 2012 IMSBC Code. If the particle density has not been determined correctly, determined using an incorrect standard or simply assumed, the TML obtained from the point at which the material reaches $70 \%$ saturation will be incorrect. This is because the saturation lines are calculated using the particle density of the sample being tested.

Because ore concentrates have been refined, the particle densities can be predictable and fairly consistent, but in contrast, the particle density of the IOF can vary significantly. During this study the particle density of samples of IOF ranged from $3.8-4.8 \mathrm{t} / \mathrm{m}^{3}$. It is critical that the particle density is measured correctly for use during the Proctor/Fagerberg test to obtain an accurate TML.

\subsubsection{Development of the Proctor/Fagerberg Test}

During research into the development of the Proctor/Fagerberg test in 1971, Fagerberg and Stavang compacted samples to different densities with hammers of different weights and drop heights, as seen in Table 1 [26].

Table 1 - Hammer weights and drop heights used during the development of the Proctor/Fagerberg test [26].

\begin{tabular}{|l|l|l|l|l|l|}
\hline $\begin{array}{l}\text { Methods } \\
\text { Tested }\end{array}$ & $\begin{array}{l}\text { Hammer Weight } \\
\text { (g) }\end{array}$ & $\begin{array}{l}\text { Height of Drop } \\
\text { (cm) }\end{array}$ & $\begin{array}{l}\text { Number of Blows per } \\
\text { Layer }\end{array}$ & $\begin{array}{l}\text { Number of } \\
\text { Layers }\end{array}$ & $\begin{array}{l}\text { Compaction Energy } \\
\text { (J) }\end{array}$ \\
\hline A & 2498 & 30.5 & 25 & 5 & 747.16 \\
\hline
\end{tabular}




\begin{tabular}{|l|l|l|l|l|l|}
\hline B & 1000 & 20.0 & 25 & 5 & 196.13 \\
\hline C & 350 & 20.0 & 25 & 5 & 68.65 \\
\hline D & 150 & 15.0 & 25 & 5 & 22.06 \\
\hline E & 50 & 4.0 & 25 & 5 & 1.96 \\
\hline
\end{tabular}

To determine the compaction effort to be used, Fagerberg and Stavang obtained core samples from 85 vessels, containing different types of ore concentrates. The samples were obtained by inserting small brass cylinders in the cargo during unloading. The undisturbed samples were then sent off to a laboratory for the determination of void ratio and moisture content. These samples were taken from different depths, with the deepest being $8 \mathrm{~m}$. They examined the results and discovered that the density produced by compaction "Method C" and "Method D" was the same density of the cargo in the vessels [26].

Figure 11 show these two compaction curves produced by Fagerberg and Stavang along with the void ratios from one of the 85 cargo vessels. Compaction "Method D" produced the most similar densities to what were measured on board the vessels, but compaction "Method C" was chosen as the preferred method because it provided an inbuilt safety factor [26].

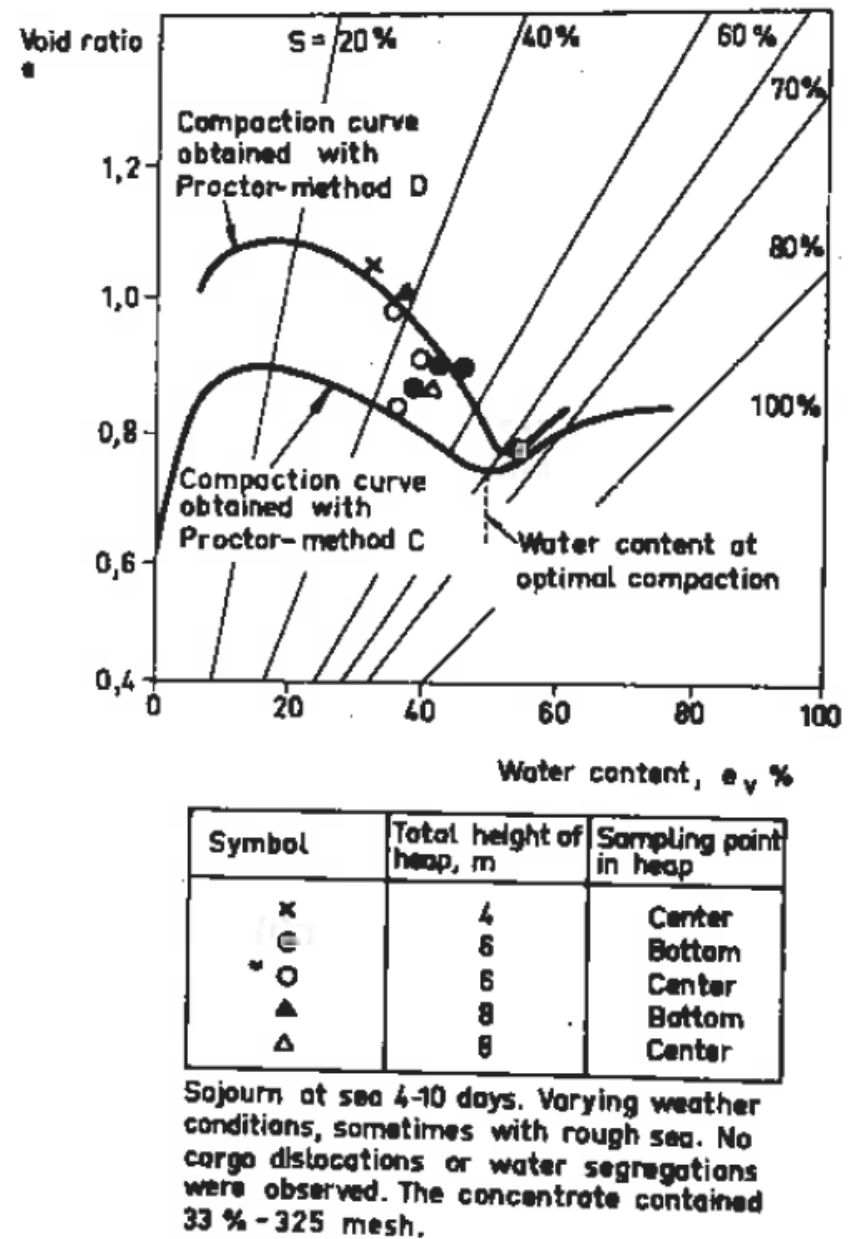

Figure 11 - Comparison by Fagerberg and Stavang in 1971 of in situ void ratios of ore concentrates on board a vessel and compaction methods $C$ and $D[26]$.

The materials that Fagerberg and Stavang tested were ore concentrates which had an optimum moisture contents of around $70 \%$ saturation. The optimum moisture content is the moisture content at which a compaction curve reaches the minimum void ratio or maximum density. Fagerberg and Stavang considered the optimum moisture content, of the ore concentrates, as the most probable point at which they would become potentially liquefiable. This is the reason behind Fagerberg and Stavang selecting $70 \%$ saturation as the point where the TML would be obtained. In the 2012 IMSBC Code, compaction "Method C" along with selecting the TML from where the compaction curve intersects $70 \%$ saturation is known as the Proctor/Fagerberg test, which is currently used to determine the TML of potentially liquefiable cargoes [2]. 


\subsection{Flow Table Test}

\subsubsection{Background}

The Flow Table test has been widely used in the cement industry to test hydraulic cement since 1983 with the release of ASTM C230 / C230M Standard Specification for Flow Table for Use in Tests of Hydraulic Cement [28]. It can be traced back to 1971 when it was used to test Portland-Cement [29] and as far back as 1952 when it was used to test Magnesium Oxychloride Cements [30]. The early BC Code included a modified procedure, created by the Department of Mines and Technical Services in Canada that can be used to determine the TML of bulk cargos using the Flow Table apparatus. In 2000, this method also branched out into the ISO Guide 12742 [31]. The following is a brief description of the Flow Table test procedure as given in the 2012 IMSBC Code [2], which also references apparatus used in ASTM C230 / C230M - 08 Standard Specification for Flow Table for Use in Tests of Hydraulic Cement [28].

\subsubsection{Procedure}

The Flow Table test is performed by placing a conical shaped mould on the centre of the Flow Table, as seen in Figure 12. The mould is filled and the material is compacted in three stages. In the first stage the mould is filled to one third its height then compacted uniformly, with 35 tamping actions, by means of an adjustable tamper, as seen in Figure 13. The second and third stages are similar except 25 and 20 tamping actions are performed, respectively. The predetermined force used for tamping is discussed in more detail in section 2.2.6.

After compaction is complete, and the excess material has been struck off with a straightedge, the mould is then carefully removed. Immediately after the mould is removed, the Flow Table is raised and dropped up to 50 times through a height of $12.5 \mathrm{~mm}$ at a rate of 25 times per minute. This procedure is then repeated at different moisture contents.

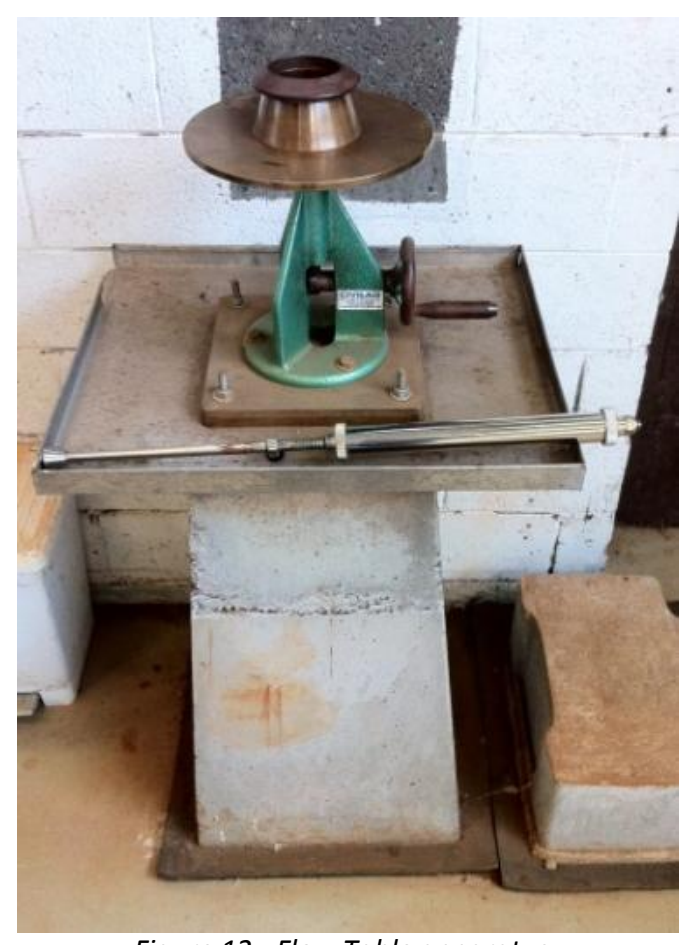

Figure 12 - Flow Table apparatus.

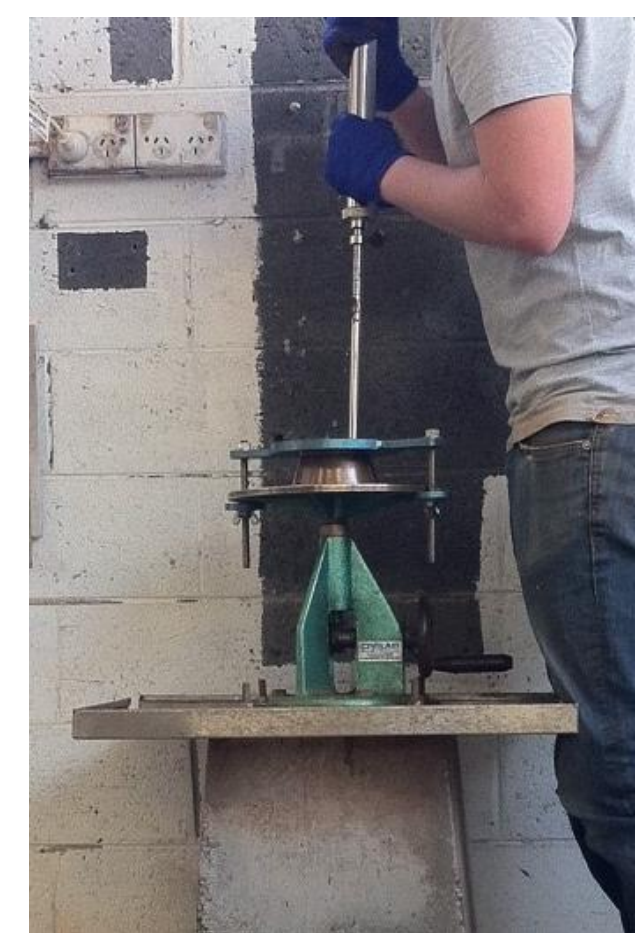

Figure 13 - Compaction into the mould on the Flow Table.

Initially, the required amount of material is mixed in a bowl and three subsamples are taken. One subsample is used to obtain the initial moisture content and the other two for the preliminary and the main Flow Table tests. The preliminary test should be performed determine the approximate moisture content at which the material will start to show plastic deformation. This point is called the flow moisture point (FMP) and in the Flow Table test it is considered to be reached when with the correct moisture content the dropping of the table produces plastic deformation of the sample, as seen in Figure 14. If the material is under the FMP the material will crumble, as seen in Figure 15. 


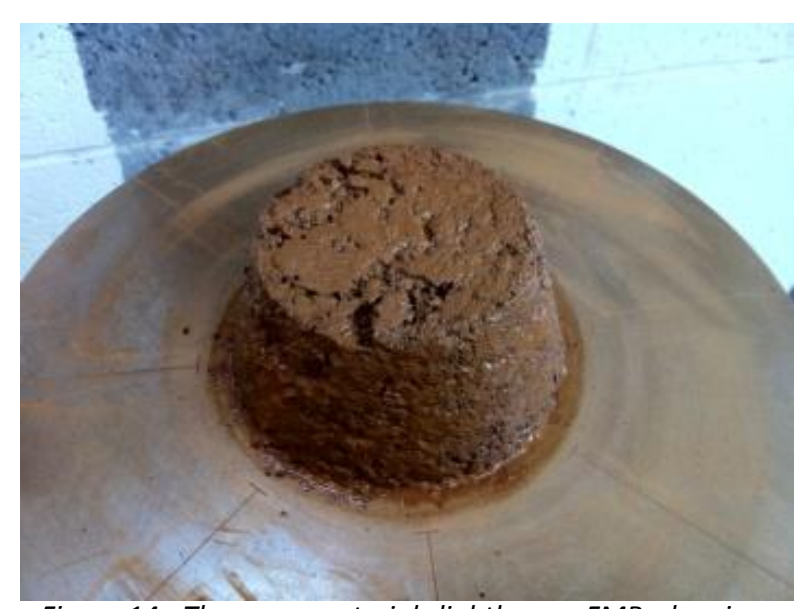

Figure 14 - The same material slightly over FMP, showing minor plastic deformation.

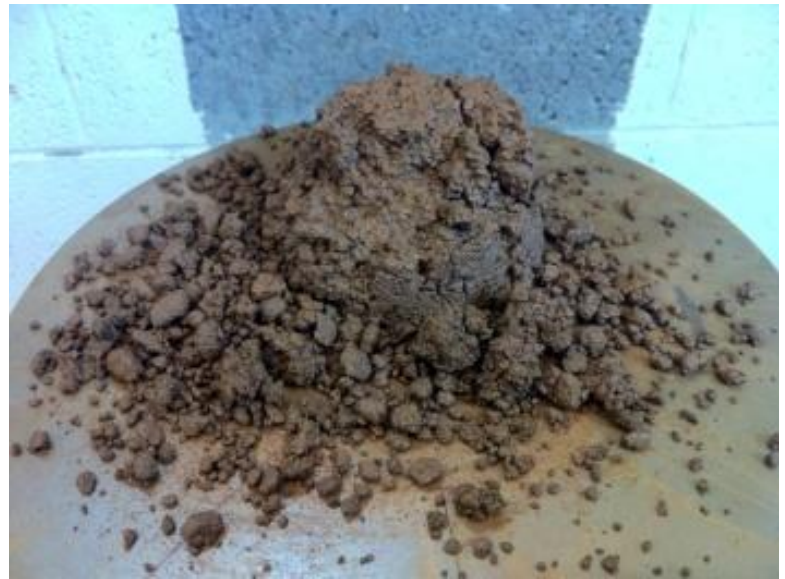

Figure 15 - Material under FMP, showing crumbling.

There are two preliminary test methods that can be used to determine the approximate moisture content at which the material will start to show plastic deformation. The first method is to wet the material, in the mixing bowl, until it is determined that the sample is over the FMP. A test is then performed on the Flow Table at this moisture content then another increment of water is added and the test is performed again. The FMP can then be estimated by plotting the moisture content against the increase in diameter. This can be seen in Figure 16. The diameter of the sample is to be measured at the end of each of the two tests and is approximately linear.

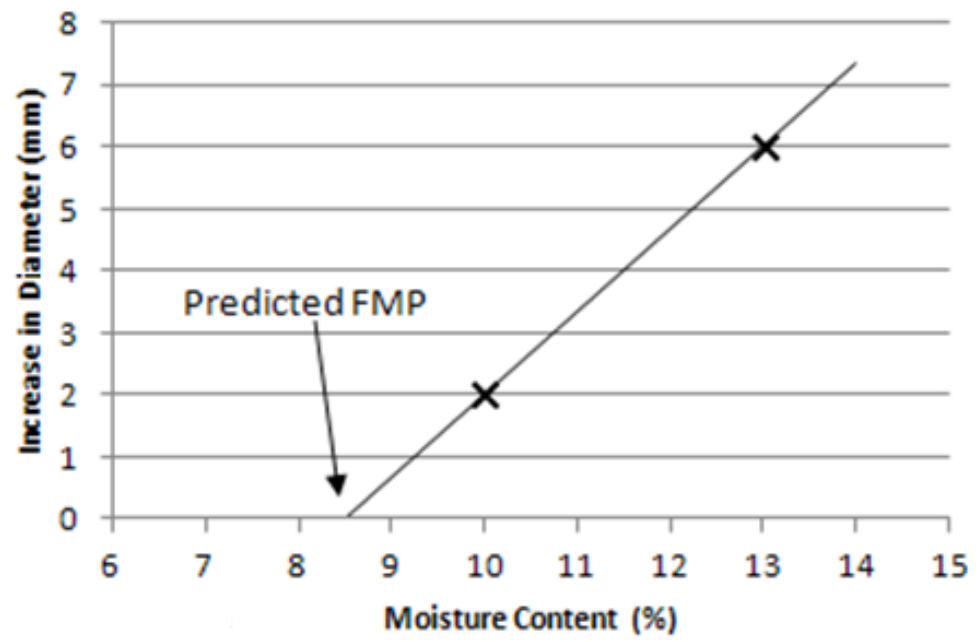

Figure 16 - The preliminary Flow Table test's graphical representation showing the approximate moisture content of the material's FMP.

The second preliminary test method involves performing the test at an initial moisture content, return the material to the mixing bowl, then mixing in $5-10 \mathrm{ml}$ of water, then repeat testing and adding known increments of water until the FMP has been reached.

After the preliminary test the main test is then performed by performing the Flow Table test on the sample at 1-2\% below the assumed FMP then adding water in increments of $0.5 \%$ of the mass of the test material. The material is retained after each test in case the FMP is reached in the subsequent test. After the FMP has been reached, the gross water content is determined on the samples just below and just above the FMP. The difference between these two gross water contents should be $0.5 \%$ or less to be in accordance with the code. The FMP is then taken as the mean of these two values and the TML is taken as $90 \%$ of the FMP. The calculations used in this test method can be seen in Appendix B.2 and typical IOF TML values for this test can be seen in Table C.2 in Appendix C.

The Flow Table test uses the least amount of material of the three tests. It needs a minimum sample size of 5-10kg for testing a sample of IOF. The use of approximately $1 \mathrm{~kg}$ of IOF per compaction point is sufficient for filling the mould with a small amount sample to spare. The 2012 IMSBC Code [2] states the Flow Table test is applicable for materials with a maximum particle size of $1 \mathrm{~mm}$, but may be applicable for materials with a maximum particle size of $7 \mathrm{~mm}$. It is not suitable for materials coarser than this or for materials with high clay content.

\subsubsection{Estimated Test Time}


According to the procedure in the 2012 IMSBC Code, if the Flow Table test is performed by an experienced operator it can be completed in three days. One day is needed to complete the preliminary test, the second to estimate the FMP from the preliminary moisture contents and then perform the main test, and the third to determine the gross water contents of the main test samples and determine the TML.

Determining the bulk density using the Proctor compaction test described in ASTM D-698 [27] or JIS-A1210 [32], which is needed to determine the tamping pressure used during the Flow Table test, can be performed on the first day prior to the preliminary test. This is because determining the moisture content for the Proctor compaction can be avoided as it is not needed to calculate the bulk density. See section 2.2.6 for more details on the compaction of the sample.

\subsubsection{Reliability}

Determining the TML of a material using the Flow Table test is the most demanding test on the operator. The operator has to visually determine whether or not the sample is above or below the FMP. Visually being able to determine the FMP of coarser samples can be difficult as coarse particles breaking off can obscure the operator's view when trying to observe plastic deformation of the sample. Although with the same laboratory and same operator the repeatability of the test is excellent, when comparing against other laboratories and operators the repeatability is not as good as the other two methods. The repeatability and reproducibility of the test can be improved with a more detailed test procedure.

\subsubsection{Application of Materials}

The Flow Table test, as seen in the 2012 IMSBC Code [2] and ISO-12742 [31], is only used for determining the TML of ore concentrates and coals. Since both standards are near identical, it can be assumed that they are used to test the same materials. In table 1.1.4.1, p. 306, of the 2012 IMSBC Code, it lists coal, metal ore, iron ore concentrate and lead ore concentrate. In the scope of ISO-12742 it states "This International Standard specifies a flow-table method for the determination of the TML of copper, lead and zinc sulfide concentrates, which may liquefy during transport". Nowhere does it refer to the TML testing of other materials, such as IOF. Further investigation is needed to determine if the Flow Table test gives accurate results when determining the TML of IOF.

\subsubsection{Compaction of the Sample}

In the Flow Table and Penetration test procedures, the 2012 IMSBC Code gives options for determining the pressure that should be used when compacting samples into the mould using the tamping rod. To determine the pressure either paragraph 1.1.4.1.2, pp. 305 (see eq. 3) or table 1.1.4.1, pp. 306 (see Table 2) of the 2012 IMSBC Code should be used [2]. IOF are not mentioned in Table 2 therefore eq. 3 must be used utilizing the bulk density determined using either ASTM D-698 [27] or JIS-A1210 [32].

Tamping Pressure $(\mathrm{Pa})=$ Bulk Density $\left(\mathrm{kg} / \mathrm{m}^{3}\right) \times$ Maximum Depth of Cargo $(\mathrm{m}) \times$ Acceleration of Gravity $\left(\mathrm{m} / \mathrm{s}^{2}\right)$ (Eq. 3) Equation reproduced from Paragraph 1.1.4.1.2, pp.305 of the 2012 IMSBC Code [2].

Table 2 - Standard tamping pressures for the Flow Table and Penetration tests according to the 2012 IMSBC Code [2].

\begin{tabular}{|l|l|l|l|l|l|}
\hline \multirow{2}{*}{ Cargo } & \multirow{2}{*}{ Bulk Density $\left(\mathbf{k g} / \mathbf{m}^{\mathbf{3}}\right)$} & \multicolumn{4}{|c|}{ Maximum Cargo Depth $(\mathbf{m})$} \\
\cline { 3 - 6 } & & $\mathbf{2 m}$ & $\mathbf{5 m}$ & $\mathbf{4 0 m}$ & $\mathbf{2 0 m}$ \\
\cline { 3 - 6 } & & $20(1.4)$ & $50(3.5)$ & $100(7.1)$ & $200(14.1)$ \\
\hline Coal & 1000 & $40(2.8)$ & $100(7.1)$ & $200(14.1)$ & $400(28.3)$ \\
\hline & 2000 & $60(4.2)$ & $150(10.6)$ & $300(21.2)$ & $600(42.4)$ \\
\hline Metal Ore & 3000 & $80(5.7)$ & $200(14.1)$ & $400(28.3)$ & $800(56.5)$ \\
\hline Iron Ore Conc. & 4000 & $100(7.1)$ & $250(17.7)$ & $500(35.3)$ & $1000(70.7)$ \\
\hline Lead Ore Conc. & 5000 & &
\end{tabular}

(Values in parenthesis are equivalent $\mathrm{kg} . f$ when applied via a $30 \mathrm{~mm}$ diameter tamping head.)

Table reproduced from Table 1.1.4.1, pp.306 of the 2012 IMSBC Code [2].

Note: The standard Proctor compaction method in ASTM D-698 [27], also known as the "Proctor C Method", is not to be confused with the Proctor/Fagerberg test, also called "Method C" by Fagerberg and Stavang during their research [26]. This is described in more detail in section 2.1.7. 
Eq. 3 and Table 2, from the 2012 IMSBC Code assumes that the cargoes have a uniform density from top to bottom therefore the tamping pressure may not be accurately reproducing the density of the cargoes in the holds of bulk carriers. As an example of this, eq. 4 shows iron ore concentrate's calculated tamping pressure for a depth of $20 \mathrm{~m}$. The values used are from Table 2 (i.e. $4000 \mathrm{~kg} / \mathrm{m}^{3}$ ).

$$
\text { Tamping Pressure }(\mathrm{Pa})=4000\left(\mathrm{~kg} / \mathrm{m}^{3}\right) \times 20(\mathrm{~m}) \times 9.81\left(\mathrm{~m} / \mathrm{s}^{2}\right)=785 \mathrm{kPa}
$$

Eq. 4 illustrates the value in Table 2 of $800 \mathrm{kPa}(\sim 785 \mathrm{kPa})$ is assuming a uniform density of $4000 \mathrm{~kg} / \mathrm{m}^{3}$ through the total height of the cargo. In reality a well graded material, such as IOF, will increase in density, from the top to the bottom of the material. This is caused by the increasing pressure, on the material below, from the material above.

One of the main contributing factors, to the resulting TML value, is the density that a sample is compacted. Based on the information obtained, the 2012 IMSBC Code [2] does not reasonably describe to what density a sample of IOF should be compacted or what tamping pressure should be used. This is true for both the Flow Table test and the Penetration test as they both utilise the same method. See section 2.3.6 for more details on the compaction method used for the Penetration test.

\subsection{Penetration Test}

\subsubsection{Background}

The Penetration test was developed in Japan at the Research Institute of Marine Engineering for determining the TML of coal [33]. It was adopted by the International Maritime Organization, between 1991 and 1998, for determining the TML of ore concentrates and coal.

\subsubsection{Procedure}

The Penetration test is performed by placing a sample, in four layers, into a cylindrical mould, as seen in Figure 17. The mould is either $1700 \mathrm{~cm}^{3}$ or $4700 \mathrm{~cm}^{3}$ in size depending on the maximum particle of the sample. For each layer, the sample is compacted with an adjustable tamper so that the sample is flat and level. It is stated by the creators of the test that regardless of the tamping pressure used, prior to vibrating, it will not affect the result because the sample is quickly consolidated by the vibrating table [33]. After compaction is complete the mould is attached to a vibrating table and a Penetration bit, that weighs $5 \mathrm{kPa}$ for coals or $10 \mathrm{kPa}$ for ore concentrates, is placed on the surface of the material, as seen in Figure 18. The vibrating table is then operated at a frequency of $50-60 \mathrm{~Hz}$ with an acceleration of $2 \mathrm{~g}$ rms $\pm 10 \%$ for 6 minutes. After 6 minutes the depth of Penetration, by the Penetration bit, is recorded.

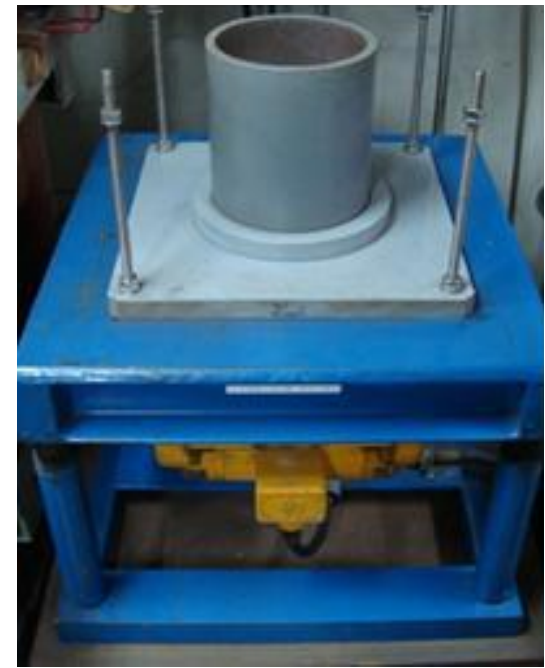

Figure 17 - Penetration test apparatus.

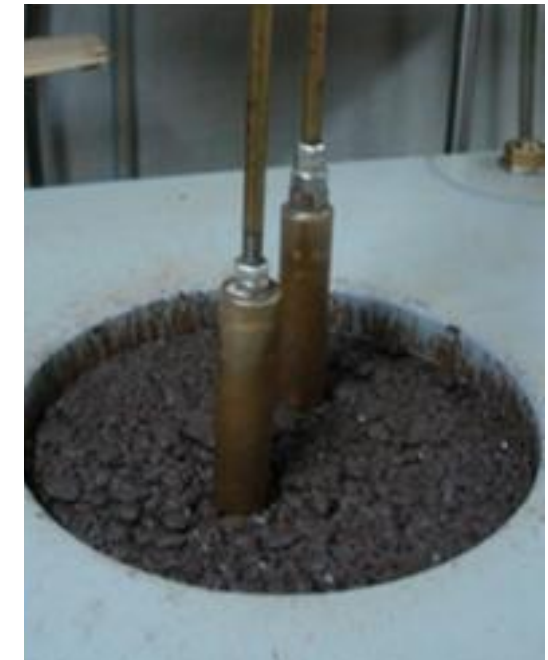

Figure 18 - Penetration bits.

Figures reproduced from DSC 17/INF.10 - Inadequacy of Current IMSBC Code Methodologies to Transportable Moisture Limit Determination on Brazilian Iron Ore Fines [34].

Initially, the required amount of material is mixed in a bowl and three subsamples are taken. One subsample is used to obtain the initial moisture content and the other two for the preliminary and the main Penetration tests. The 
preliminary test is performed to determine the approximate moisture content at which the depth of penetration, by the penetration bits, will be greater than $50 \mathrm{~mm}$. During the Penetration test, the point at which the depth of Penetration is greater than $50 \mathrm{~mm}$ is called the flow moisture point (FMP).

The preliminary test procedure involves mixing water into the material, in increments of $1 \%$ of the mass of the subsample then performing the procedure described above. When the depth of Penetration is less than $50 \mathrm{~mm}$, it is judged that the FMP has not been reached. If this is so, the material is removed from the mould and recombined with the initial sample and an additional increment of water is added. These steps are repeated until the depth of Penetration is greater than $50 \mathrm{~mm}$. The material is then removed from the mould and the gross water content determined. This will be the gross water content of the sample above the FMP. The gross water content just below the FMP is then calculated based on the amount of water added. The average of these two values is the assumed FMP of the sample and this value is used to perform the main test.

The main test is similar to the preliminary test but is intended to be more accurate. Water is added to the remaining subsample until the moisture content just below the assumed FMP. The first main test is performed on the material at this moisture content then additional water is added in increments of no more than $0.5 \%$ of the mass of the test material, retaining the material that was tested each time in case the FMP is reached in the subsequent test. When the depth of Penetration is greater than $50 \mathrm{~mm}$ the FMP has been reached and the gross water content is determined on this sample and the preceding sample. These two samples should be just below and just above the FMP and the difference between the two sample's gross water contents should be no more than $0.5 \%$. The FMP is then taken as the mean of these two values and the TML is taken as $90 \%$ of the FMP. The calculations used for the Penetration test are the same as the Flow Table test and can be seen in Appendix B.2 and typical IOF TML values for this test, reported by Brazil, can be seen in Table C.3 in Appendix C [34].

The sample size needed to complete a Penetration test can vary significantly depending on the mould size that is needed. $25 \mathrm{~kg}$ of IOF are needed if the maximum particle size of the material is $10 \mathrm{~mm}\left(1700 \mathrm{~cm}^{3}\right.$ mould $)$ or $70 \mathrm{~kg}$ is needed if the maximum particle size of the material is $25 \mathrm{~mm}\left(4700 \mathrm{~cm}^{3}\right.$ mould). The Penetration test can be performed on materials with a maximum particle size of $25 \mathrm{~mm}$.

\subsubsection{Estimated Test Time}

According to the procedure in the 2012 IMSBC Code, the Penetration test can be completed in two days. This is if the test is performed by an experienced operator and the preliminary test's FMP is calculated based on moisture added instead of oven drying the samples to determine the moisture contents. One day is needed to complete the preliminary test, estimate FMP and then perform the main test. The second day is needed to weigh up the samples that were dried out during the main test and then calculate the TML.

Determining the bulk density using the Proctor compaction test described in ASTM D-698 [27] or JIS-A1210 [32], which is needed to determine the tamping pressure used during the Penetration test, can be performed on the first day prior to the preliminary test. This is because determining the moisture content for the Proctor compaction can be avoided as it is not needed to calculate the bulk density. See section 2.3.6 for more details on the compaction of the sample.

\subsubsection{Reliability}

The Penetration test uses measurements to determine whether the FMP has been reached and does not need the operator to interpret visually whether this point has been reached. The test is repeatable between operators and laboratories as long as the same procedure is used. Varying the settings on the vibrating table can cause significant differences in the results and more investigation is needed to determine if the initial compacted density, produced by the tamper, effects the resulting TML. More information regarding compaction of the sample can be seen in section 2.3.6.

\subsubsection{Application of Materials}

The Penetration test was developed in Japan at the Research Institute of Marine Engineering [33] and is stated as being "applicable to coals and similar materials" [35]. When the test was incorporated into the 2012 IMSBC Code [2], there were no studies completed to see if it is reliable for determining the TML of IOF.

\subsubsection{Compaction of the Sample}


The Penetration test refers to the compaction effort performed in the Flow Table test. The 2012 IMSBC Code states to "tamp to a pressure denoted in 1.1.4.1 (Flow table preparation procedure) for mineral concentrates or to $40 \mathrm{kPa}$ for coals, and apply the pressure evenly over the whole surface area of the material until a uniformly flat surface is obtained" [2]. The 2012 IMSBC Code does not state the number of tamping actions required.

Furthermore during initial studies, it was stated that "the tamping does not affect the result of the Penetration test, because the sample is quickly consolidated by vibration regardless of the pressure of tamping conducted prior to the test. In order to get a smooth surface, $0.42 \mathrm{~kg} . \mathrm{f} / \mathrm{cm}^{2}$ in tamping pressure is recommendable." [33]. For the testing of IOF, further studies are required to determine if the density achieved by vibration in the Penetration test is representative of that in a bulk carrier's hold and if the tamping pressure affects the resulting TML.

\section{Materials}

The typical properties of IOF that were tested during this study can be seen in in Table 3 to Table 5. The IOF that were tested were obtained from various locations around Australia.

Table 3 - Typical properties of IOF tested during this study.

\begin{tabular}{|l|l|l|l|l|}
\hline & Minimum & Maximum & Average & Standard \\
\hline Initial Moisture Content (\%) & 3.42 & 10.30 & 7.86 & AS1289.2.1.1 \\
\hline Particle Density $\left(\mathbf{t} / \mathbf{m}^{\mathbf{3}} \mathbf{)}\right.$ & 3.78 & 4.91 & 4.27 & AS1289.3.5.1 \\
\hline
\end{tabular}

Table 4 - Typical properties of a sample of IOF that were tested during this study.

\begin{tabular}{|c|c|c|}
\hline & & Standard \\
\hline Minimum Dry Density $\left(\mathrm{t} / \mathrm{m}^{3}\right)$ & 2.12 & AS1289.5.5.1 \\
\hline Maximum Dry Density $\left(\mathrm{t} / \mathrm{m}^{3}\right)$ & 3.08 & AS1289.5.5.1 \\
\hline Liquid Limit (\%) & 18.00 & AS1289.3.1.2 \\
\hline Plastic Limit (\%) & 16.00 & AS1289.3.2.1 \\
\hline Plasticity Index (\%) & 2.00 & AS1289.3.3.1 \\
\hline Standard Proctor Compaction - Optimum Moisture Content (\%) & 12.00 & AS1289.5.1.1 \\
\hline Standard Proctor Compaction - Maximum Dry Density $\left(\mathrm{t} / \mathrm{m}^{3}\right)$ & 2.73 & AS1289.5.1.1 \\
\hline
\end{tabular}

Table 5 - Typical particle size distribution data, obtained using AS1289.3.6.1, of IOF tested during this study.

\begin{tabular}{|c|c|c|c|}
\hline & Minimum & Maximum & Average \\
\hline$\%$ Clay $(<75 \mu \mathrm{m})$ & 2.60 & 6.50 & 4.74 \\
\hline$\%$ Silt (2-60 $\mu \mathrm{m})$ & 4.70 & 19.10 & 14.33 \\
\hline$\%$ Sand $(0.06-2 \mathrm{~mm})$ & 42.00 & 58.70 & 48.36 \\
\hline$\%$ Gravel $(2-60 \mathrm{~mm})$ & 21.10 & 45.50 & 33.30 \\
\hline Nominal Particle Size (mm) & 0.075 & 2.36 & 2.36 \\
\hline Maximum Particle Size (mm) & 4.75 & 13.20 & 9.50 \\
\hline Coefficient of Uniformity $\left(C_{u}\right)$ & 24.86 & 273.16 & 119.30 \\
\hline Coefficient of Curvature $\left(C_{c}\right)$ & 0.65 & 7.44 & 1.72 \\
\hline
\end{tabular}

Note 1: The boundaries of the IOF particle size distributions tested during this study can be seen in Figure 19.

Note 2: All properties listed in Table 3 to Table 5 were performed in accordance with AS1289.0-2000 - Method of testing soils for engineering purposes [36].

Note 3: Not all of the samples used to obtain the typical physical properties of IOF provided in Table 3 to Table 5 were tested during this study.

From the IOF tested, a significant variation in the physical properties was noticed depending on the location from where it was extracted. One main property of IOF which determine the moisture content at which it may become potentially liquefiable is the particle size distribution. Some samples of IOF contain significant amounts of large particles which, according to Ishihara [37], reduce the potential to liquefy. Shown in Figure 19 are the boundaries of potentially liquefiable materials when compared with their particle size distributions. By overlaying the particle size 
distributions of the IOF tested during this study, it shows that some samples tested may have more of a potential to liquefy than others.

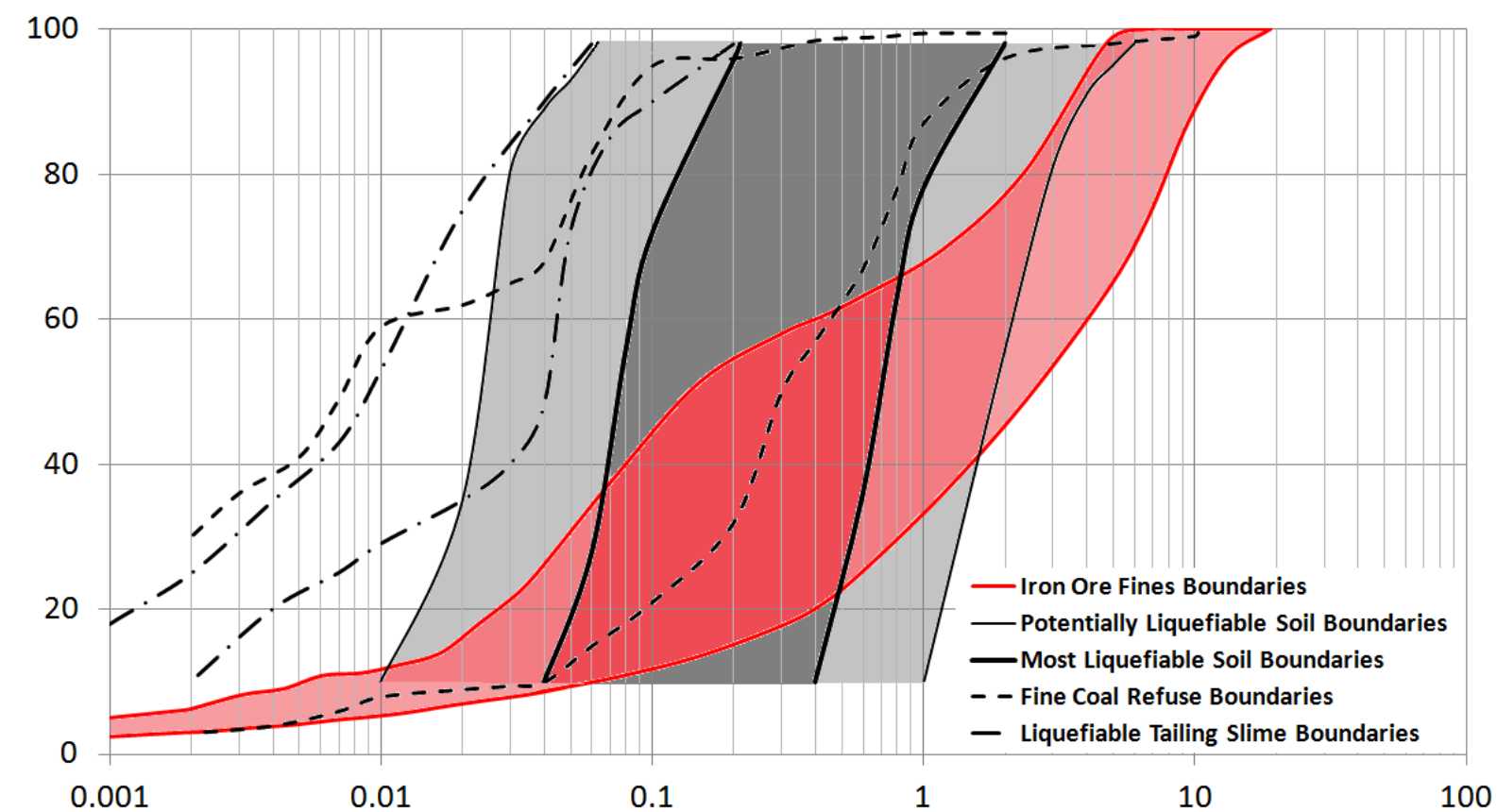

Figure 19 - Particle size distribution boundaries of liquefiable materials, determined by Ishihara [37], and boundaries of IOF determined during this study.

During this study the samples of IOF tested were not modified to reduce the particle size to be in accordance with the maximum particle sizes listed for the TML test procedures in the 2012 IMSBC Code [2]. Reducing the particle size will change the total particle surface area and therefore the moisture holding abilities of the sample will increase.

The 2012 IMSBC Code states the maximum particle size permissible for each of the three test methods [2]. The Penetration test can be performed on materials with a maximum particle size of $25 \mathrm{~mm}$. As part of this study, the particle size distributions of the samples of IOF were tested and the maximum particle size overall was found to be $13.2 \mathrm{~mm}$, therefore less than the 2012 IMSBC Code's limitation of $25 \mathrm{~mm}$.

The 2012 IMSBC Code states that the Proctor/Fagerberg test is only suitable for samples with a maximum particle size of $5 \mathrm{~mm}$. All the samples of IOF tested during this study contain particles greater than $5 \mathrm{~mm}$ with the average being $15 \%$ retained on the $4.75 \mathrm{~mm}$ (No. 4) sieve. This said, the results from testing IOF, with $15-20 \%$ greater than $4.75 \mathrm{~mm}$, using the Proctor/Fagerberg test method, correlates with the results from the Flow Table and Penetration test methods, as seen in Figure 21, Figure 27 and Figure 28, therefore the small amount of large particles do not seem to affect the results of the test. Further investigation into the effects of particle size on the Proctor/Fagerberg test is needed when testing coarse materials, such as IOF.

The 2012 IMSBC Code states that the Flow Table test is applicable for materials with a maximum particle size of $1 \mathrm{~mm}$, but may be applicable for materials with a maximum particle size of $7 \mathrm{~mm}$. It also states that it is not suitable for materials with high clay content. From the samples of IOF tested the average material retained on the $6.7 \mathrm{~mm}$ $(0.265 ")$ sieve was approximately $7 \%$. This small amount of coarse material does not seem to affect the matrix of the finer particles in the samples during testing on the Flow Table. The problem with the coarser material is that it interferes with the operator's interpretation of the FMP.

There is a limitation to the TML testing of IOF using the Flow Table and Proctor/Fagerberg test methods based on the particle size of the material and the limiting size stated in the 2012 IMSBC Code [2]. Further studies are required to determine the effect of particle size while performing the Flow Table and Proctor/Fagerberg tests.

\section{Experimental Results from this Study}

During this research we performed testing to determine the TML of IOF using the Proctor/Fagerberg and Flow Table test methods. The Penetration test was not able to be performed due to not having the available apparatus. For this 
reason we have included results for the Penetration test in section 5 where supporting results are compared with the experimental results from this study.

\subsection{Proctor/Fagerberg and Flow Table TML Results}

When comparing the TML values, of IOF, obtained using the Proctor/Fagerberg and Flow Table test methods we can clearly see a variation in the results. The Proctor/Fagerberg test produces a higher TML value when compared with the Flow Table TML. Figure 20 and Table 6 show the Proctor/Fagerberg TML value can be up to $16 \%$ greater than the Flow Table TML. Another representation of the data in Table 6 can be seen in Figure 21. The results correlate well $\left(R^{2}\right.$ $=0.97)$, but vary from the equality line significantly $\left(\mathrm{Y}_{\mathrm{FT}}=0.71 \mathrm{X}_{\mathrm{PF}}+1.98\right)$.

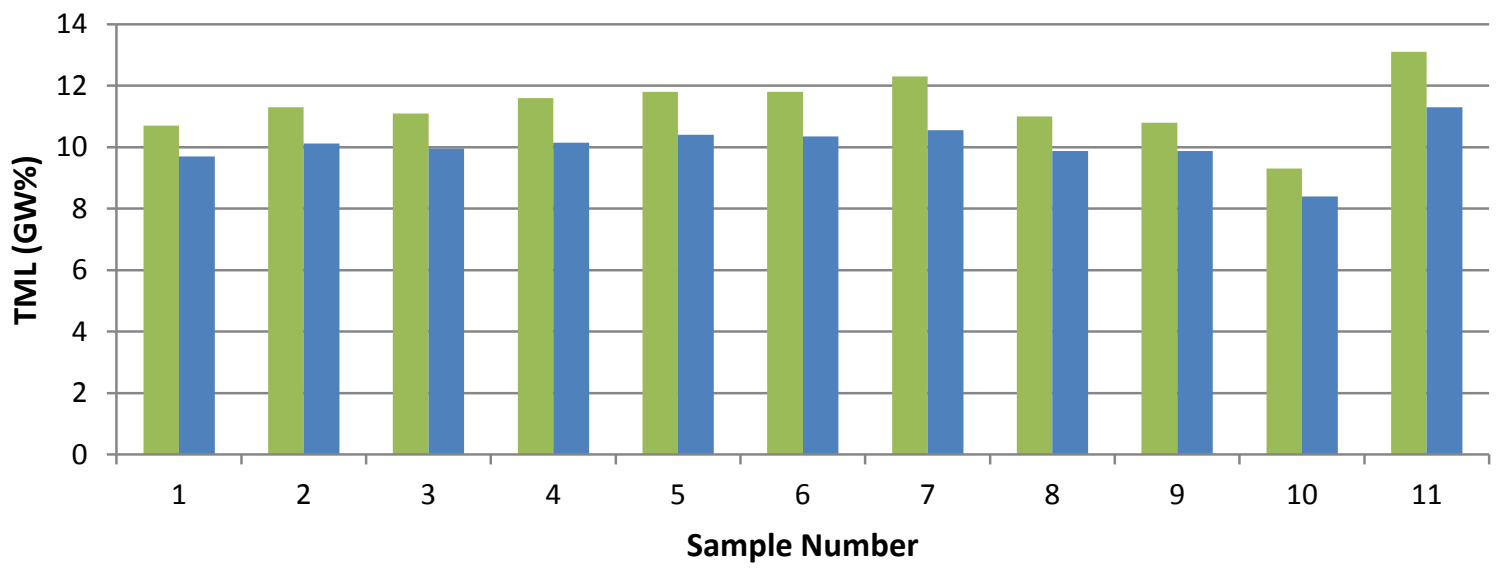

Proctor/Fagerberg TML $\square$ Flow Table TML

Figure 20 - Comparison of IOF TML values using the Proctor/Fagerberg and Flow Table tests.

Table 6 - Comparison of IOF TML values using the Proctor/Fagerberg and Flow Table tests.

\begin{tabular}{|l|l|l|l|l|}
\hline Sample & $\begin{array}{l}\text { Proctor/Fagerberg TML } \\
\text { (GW\%) }\end{array}$ & $\begin{array}{l}\text { Flow Table TML } \\
\text { (35kg.f) (GW\%) }\end{array}$ & $\begin{array}{l}\text { Difference between PF } \\
\text { and FT TML Values (GW\%) }\end{array}$ & $\begin{array}{l}\text { Percent Difference between } \\
\text { PF and FT TML Values (\%) }\end{array}$ \\
\hline $\mathbf{1}$ & 10.7 & 9.7 & 1.0 & 10.3 \\
\hline $\mathbf{2}$ & 11.3 & 10.1 & 1.2 & 11.9 \\
\hline $\mathbf{3}$ & 11.1 & 10.0 & 1.1 & 11.0 \\
\hline $\mathbf{4}$ & 11.6 & 10.2 & 1.4 & 13.7 \\
\hline $\mathbf{5}$ & 11.8 & 10.4 & 1.4 & 13.5 \\
\hline $\mathbf{6}$ & 11.8 & 10.4 & 1.4 & 13.5 \\
\hline $\mathbf{7}$ & 12.3 & 10.6 & 1.7 & 16.0 \\
\hline $\mathbf{8}$ & 11.0 & 9.9 & 1.1 & 11.1 \\
\hline $\mathbf{9}$ & 10.8 & 9.9 & 0.9 & 9.1 \\
\hline $\mathbf{1 0}$ & 9.3 & 8.4 & 0.9 & 10.7 \\
\hline $\mathbf{1 1}$ & 13.1 & 11.3 & 1.8 & 15.9 \\
\hline Average & $\mathbf{1 1 . 4}$ & $\mathbf{1 0 . 1}$ & $\mathbf{1 . 3}$ & $\mathbf{1 2 . 4}$ \\
\hline
\end{tabular}




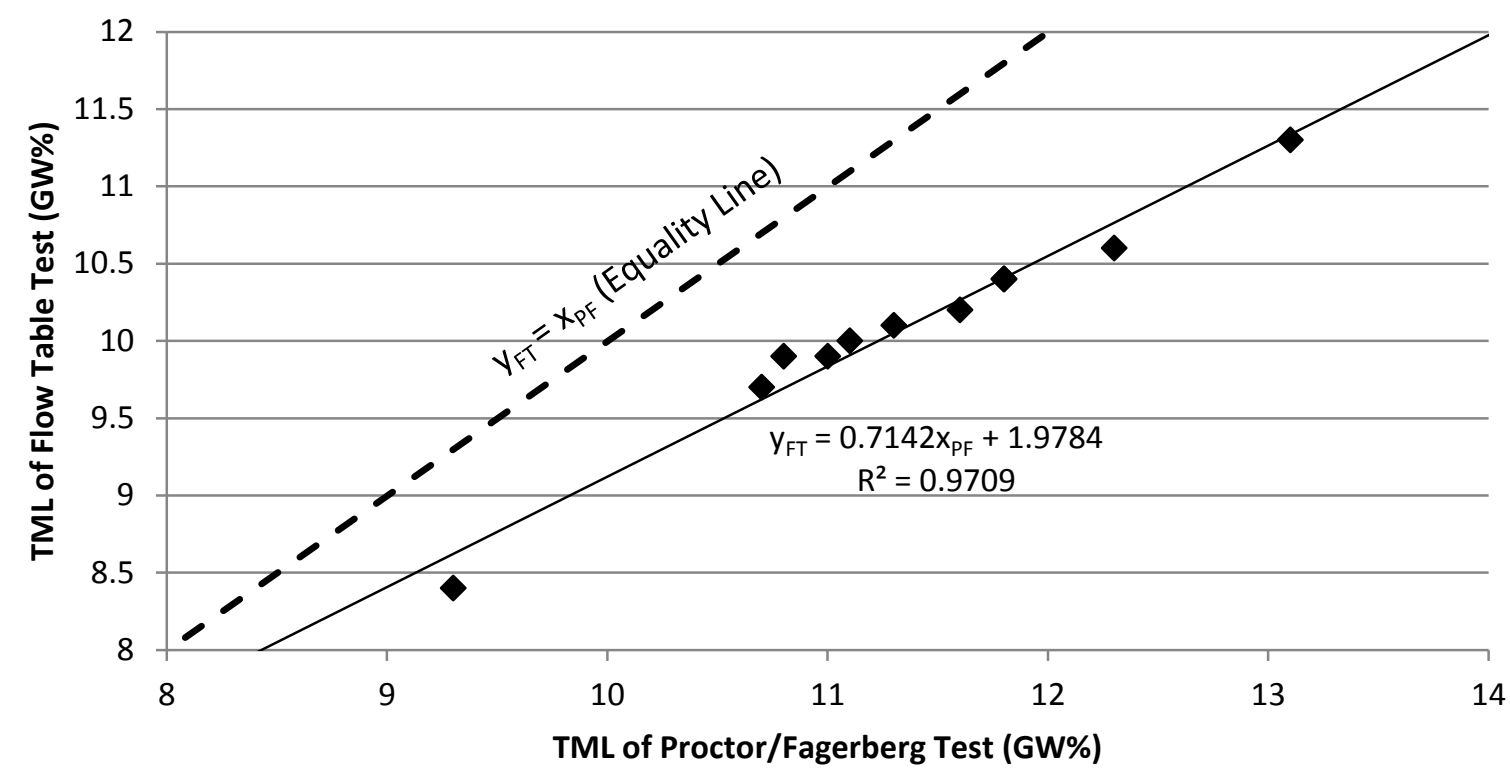

Figure 21 - Comparison of IOF TML values using the Proctor/Fagerberg and Flow Table tests.

Based on the data obtained during this study the Proctor/Fagerberg test will produce a higher TML value than the Flow Table test when testing samples of IOF.

\subsection{Proctor/Fagerberg and Flow Table Compaction Comparisons}

The IMSBC Code states, in the Proctor/Fagerberg test, that "the critical moisture content is indicated by the intersection of the compaction curve and the line $S=70 \%$ degree of saturation. The TML is the critical moisture content" [2]. Fagerberg and Stavang note that during compaction "it is a characteristic of all concentrates investigated that the voids are then filled by water to $70-75 \%$ by volume" [26]. Figure 22 show a typical Proctor/Fagerberg compaction curve of a sample of IOF. The characteristics of IOF investigated were that the voids are filled by water to $90-95 \%$ by volume and not $70-75 \%$. This characteristic of IOF can be attributed to the material being well graded when compared with the materials tested by Fagerberg and Stavang, seen in Figure 11 (section 2.1.7), and therefore can reach higher degrees of saturation.

Figure 22 also show a compaction curve produced by the Flow Table test. The flow Table test was performed at a tamping pressure to replicate the density produced by the Proctor/Fagerberg test (10kg.f). When comparing the Flow Table TML and the Proctor/Fagerberg FMP, where the FMP is the point at which the material on the Flow Table begins to show plastic deformation, the Flow Table FMP is significantly higher, as seen in Figure 22 and Table 7 . The comparison between the Flow Table FMP and the Proctor/Fagerberg TML is being used to eliminate the Flow Table safety factor, where $90 \%$ of the Flow Table FMP is the Flow Table TML. This is described in more detail in section 4.3. 


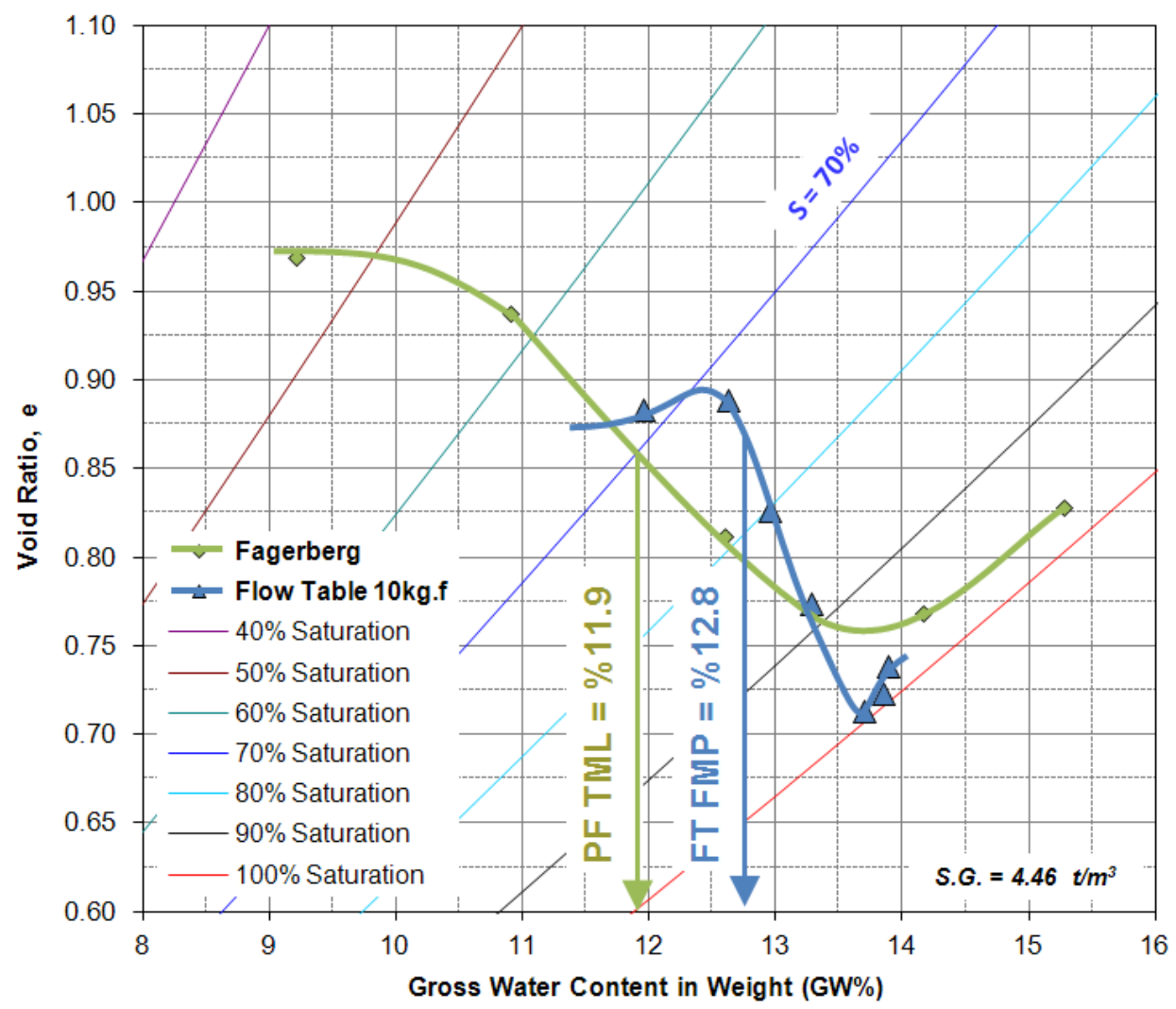

Figure 22 - Proctor/Fagerberg compaction curve compared with the Flow Table compaction curve (10kg.f) for the same sample of IOF.

Table 7 - Proctor/Fagerberg TML value compared with the Flow Table FMP value (10kg.f) for the same sample of IOF.

\section{Proctor/Fagerberg TML}

Flow Table (10kg.f) FMP

\section{$11.9 \%$}

$12.8 \%$

To determine the actual tamping pressure needed to perform the Flow Table test, the maximum bulk density was determined on the sample of IOF and was found to be $3075 \mathrm{~kg} / \mathrm{m}^{3}$ (section 3, Table 4). The tamping pressure, seen in eq. 5, was obtained using the equation given in the 2012 IMSBC Code (paragraph 1.1.4.1.2, pp. 305) [2].

Tamping Pressure $(\mathrm{Pa})=3075\left(\mathrm{~kg} / \mathrm{m}^{3}\right) \times 20(\mathrm{~m}) \times 9.81\left(\mathrm{~m} / \mathrm{s}^{2}\right)=603 \mathrm{kPa}$

According to table 1.1.4.1 of the 2012 IMSBC Code, $603 \mathrm{kPa}$ is approximately $42 \mathrm{~kg}$.f when applied to a sample in the Flow Table test through a tamper with a $30 \mathrm{~mm}$ diameter head [2]. To compare the TML using the calculated tamping effort, the same sample used in Figure 22 was again compacted except this time using $35 \mathrm{~kg} . f$. $35 \mathrm{~kg} . f$ was used instead of $42 \mathrm{~kg}$.f due to this being the maximum tamping effort the tamping rod we had could apply. Figure 23 and Table 8 show the difference in densities between the calculated tamping effort ( $35 \mathrm{~kg} . \mathrm{f})$ and the tamping effort equivalent to the Proctor/Fagerberg test (10kg.f). 


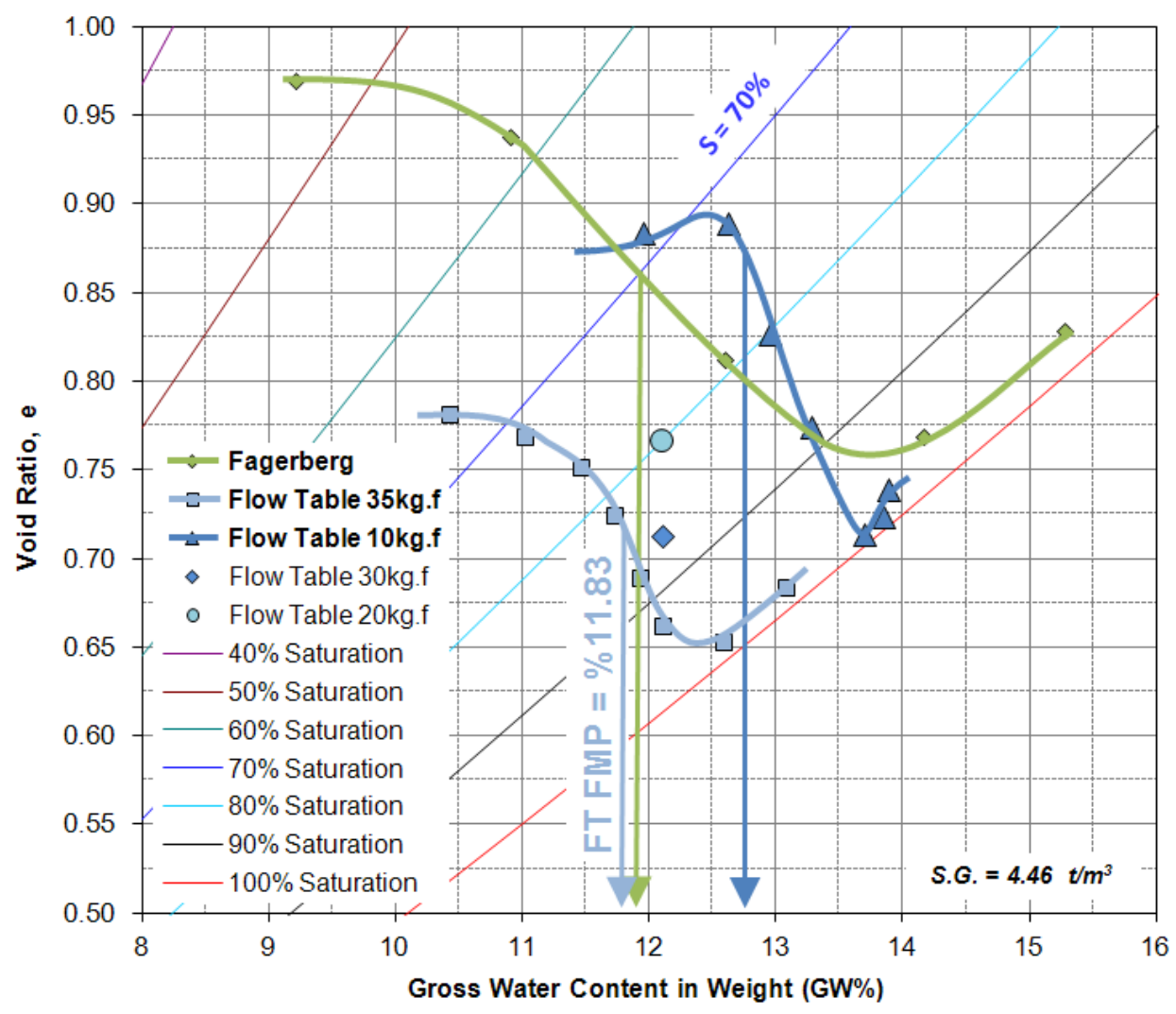

Figure 23 - IOF Proctor/Fagerberg TML value compared with the Flow Table FMP values at $35 \mathrm{~kg} . f$ and $10 \mathrm{~kg} . f$.

Note 1: One point compacted at $30 \mathrm{~kg} . \mathrm{f}$ and $20 \mathrm{~kg} . \mathrm{f}$ is also shown.

Note 2: The different shaped compaction curves, created by the Proctor/Fagerberg and Flow Table tests, are attributed to the different types of compaction energies being applied (i.e. Flow Table using a tamping rod and Proctor/Fagerberg using a compaction hammer).

Table 8-IOF Proctor/Fagerberg TML value compared with the Flow Table FMP values at $35 \mathrm{~kg} . f$ and $10 \mathrm{~kg} . f$.

\begin{tabular}{|l|l|}
\hline Proctor/Fagerberg TML & $11.9 \%$ \\
\hline Flow Table (10kg.f) FMP & $12.8 \%$ \\
\hline Flow Table (35kg.f) FMP & $11.8 \%$ \\
\hline
\end{tabular}

From the 1971 paper written by Fagerberg and Stavang [26], it has been determined that the Proctor/Fagerberg test was initially designed for determining the TML of ore concentrates and not for use with IOF. The Proctor/Fagerberg test, as stated in the 2012 IMSBC Code [2], does not seem to portray the methodology behind the procedure created by Fagerberg and Stavang. In their paper, it does not state that at $70 \%$ saturation the moisture content is equal to the TML for all materials. They state that at $70-75 \%$ saturation the ore concentrates that they tested reached minimum void ratio or maximum density and therefore this is the point at which they will be most likely to liquefy [26]. IOF reach minimum void ratio or maximum density at approximately $90-95 \%$ saturation. If comparing to the Flow Table test, a sample of IOF shows no plastic deformation at $70 \%$ saturation as seen by the Flow Table FMP results see in Figure 23. If the 2012 IMSBC Code Flow Table procedure is followed, at $80-85 \%$ saturation the samples of IOF start to show plastic deformation. Further studies are required to determine what combination of degree of saturation and density govern IOF's potential to liquefy.

\subsection{Proctor/Fagerberg and Flow Table Safety Factors}

When the FMP is found using the Flow Table and Penetration test procedures a safety factor is used to calculate the TML. The safety factor is incorporated into the procedures to compensate for operator error. The Proctor/Fagerberg test does not include a safety factor in the calculations, instead a slightly heavier hammer was chosen to incorporate a safety factor into the test [26], see section 2.1.7.

Figure 24 and Table 9 is the combined data from Table 6 and Table 10, which are the Proctor/Fagerberg TML and Flow Table TML values from multiple tests on IOF. The difference is the Flow Table FMP has been used instead of the 
TML. The Flow Table FMP is the TML with the $10 \%$ safety factor removed. Figure 24 and Table 9 show that the Proctor/Fagerberg TML value is similar when compared with the Flow Table FMP. The Proctor/Fagerberg TML value is now only on average $3 \%$ greater than the Flow Table TML.

As before, another representation of the data in Table 9 can be seen in Figure 25. The correlation between the two test methods values is the same $\left(R^{2}=0.92\right)$, but now they don't vary from the equality line as significantly as Figure 21 and Figure $28\left(\mathrm{Y}_{\mathrm{FT}}=\mathrm{X}_{\mathrm{PF}}+0.13\right)$.

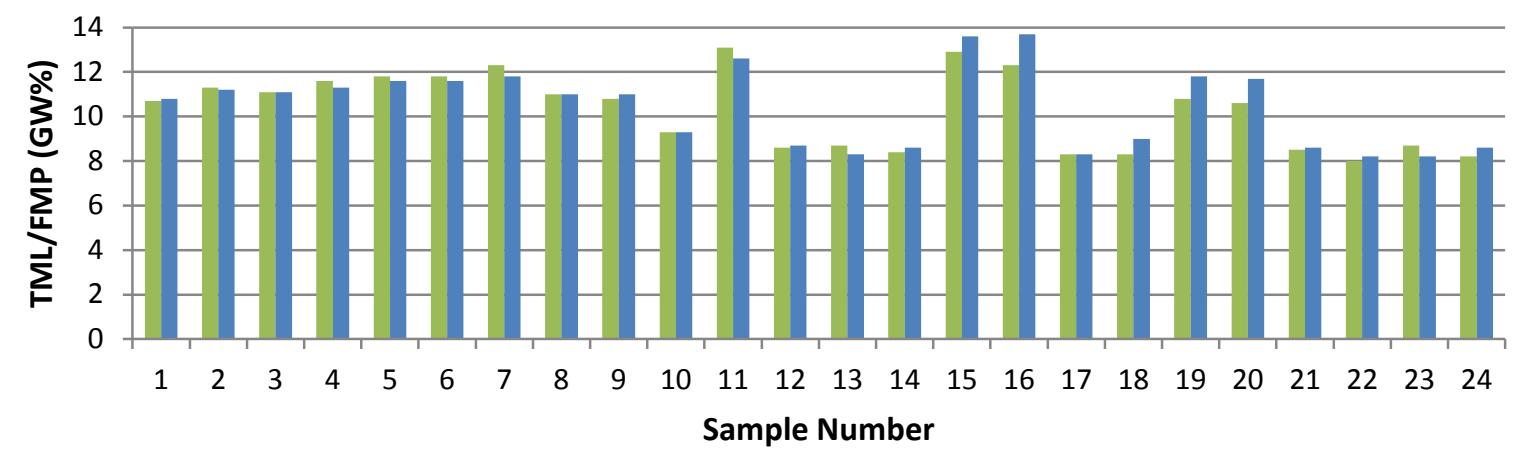

- Proctor/Fagerberg TML $\quad$ Flow Table FMP

Figure 24 - Comparison of IOF Proctor/Fagerberg TML value and Flow Table FMP value. Data from Brazil is integrated with the results from this study [34].

Table 9 - Comparison of IOF Proctor/Fagerberg TML value and Flow Table FMP value.

\begin{tabular}{|l|l|l|l|l|}
\hline Sample & $\begin{array}{l}\text { Proctor/Fagerberg TML } \\
\text { (GW\%) }\end{array}$ & $\begin{array}{l}\text { Flow Table FMP } \\
\text { (35kg.f) }\end{array}$ & $\begin{array}{l}\text { Difference between PF } \\
\text { TML and FT FMP (GW\%) }\end{array}$ & $\begin{array}{l}\text { Percent Difference between } \\
\text { PF TML and FT FMP (\%) }\end{array}$ \\
\hline $\mathbf{1}$ & 10.7 & 10.8 & 0.1 & 0.7 \\
\hline $\mathbf{2}$ & 11.3 & 11.2 & 0.1 & 0.7 \\
\hline $\mathbf{3}$ & 11.1 & 11.1 & 0.0 & 0.1 \\
\hline $\mathbf{4}$ & 11.6 & 11.3 & 0.3 & 2.4 \\
\hline $\mathbf{5}$ & 11.8 & 11.6 & 0.2 & 2.1 \\
\hline $\mathbf{6}$ & 11.8 & 11.6 & 0.2 & 2.1 \\
\hline $\mathbf{7}$ & 12.3 & 11.8 & 0.5 & 4.4 \\
\hline $\mathbf{8}$ & 11.0 & 11.0 & 0.0 & 0.0 \\
\hline $\mathbf{9}$ & 10.8 & 11.0 & 0.2 & 1.8 \\
\hline $\mathbf{1 0}$ & 9.3 & 9.3 & 0.0 & 0.4 \\
\hline $\mathbf{1 1}$ & 13.1 & 12.6 & 0.5 & 4.3 \\
\hline $\mathbf{1 2}$ & 8.6 & 8.7 & 0.1 & 0.8 \\
\hline $\mathbf{1 3}$ & 8.7 & 8.3 & 0.4 & 4.4 \\
\hline $\mathbf{1 4}$ & 8.4 & 8.6 & 0.2 & 1.8 \\
\hline $\mathbf{1 5}$ & 12.9 & 13.6 & 0.7 & 4.8 \\
\hline $\mathbf{1 6}$ & 12.3 & 13.7 & 1.4 & 10.0 \\
\hline $\mathbf{1 7}$ & 8.3 & 8.3 & 0.0 & 0.4 \\
\hline $\mathbf{1 8}$ & 8.3 & 9.0 & 0.7 & 7.8 \\
\hline $\mathbf{1 9}$ & 10.8 & 11.8 & 1.0 & 8.3 \\
\hline $\mathbf{2 0}$ & 10.6 & 11.7 & 1.1 & 9.1 \\
\hline $\mathbf{2 1}$ & 8.5 & 8.6 & 0.1 & 0.7 \\
\hline $\mathbf{2 2}$ & 8.0 & 8.2 & 0.2 & 2.7 \\
\hline $\mathbf{2 3}$ & 8.7 & 8.2 & 0.5 & 5.8 \\
\hline $\mathbf{2 4}$ & 8.2 & 8.6 & 0.4 & $\mathbf{3}$ \\
\hline $\mathbf{A v e r a g e}$ & $\mathbf{1 0 . 3}$ & $\mathbf{1 0 . 4}$ & $\mathbf{0 . 4}$ & \\
\hline & & & & 3.3 \\
\hline
\end{tabular}




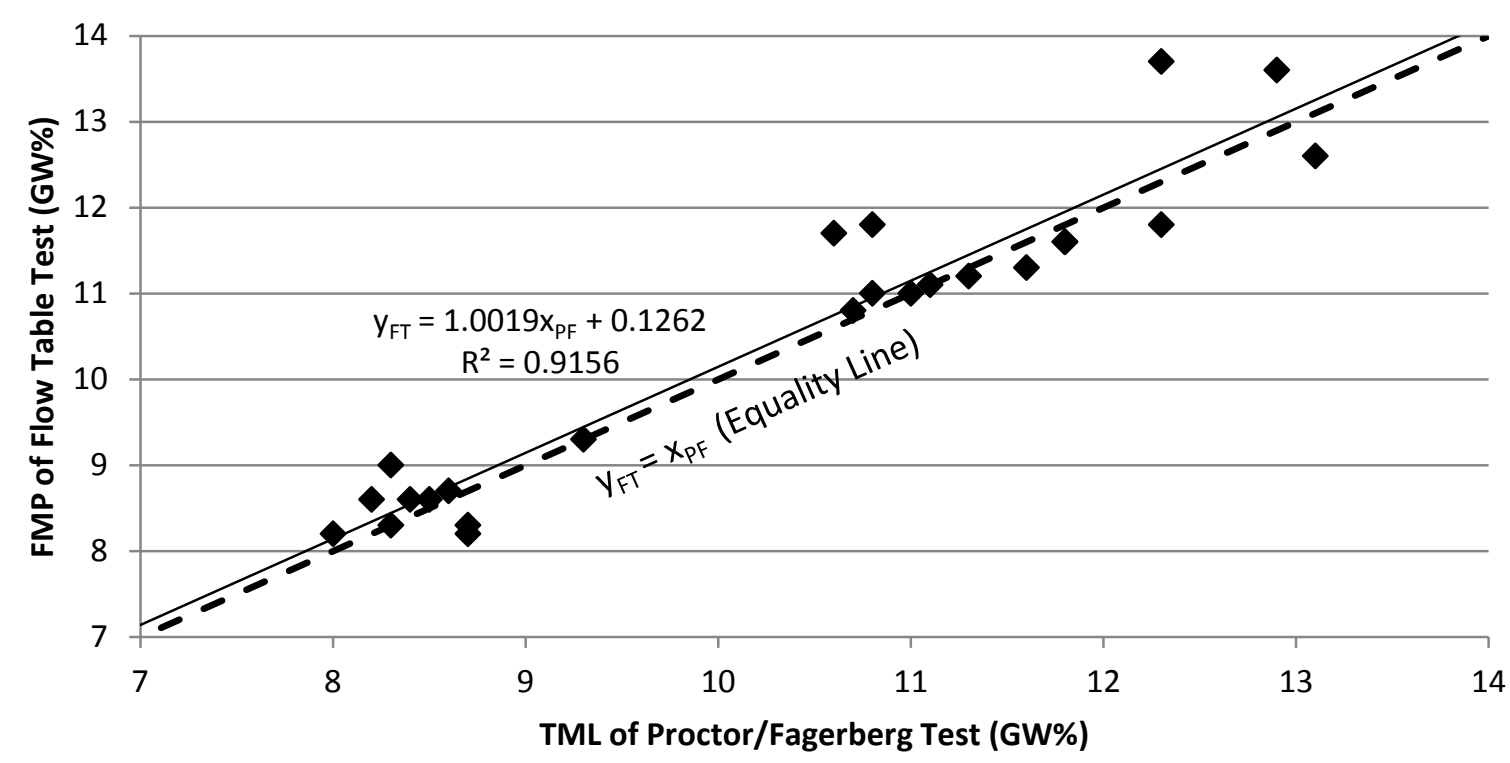

Figure 25 - Comparison of IOF Proctor/Fagerberg TML value and Flow Table FMP value.

This leads to the conclusion that when testing IOF the Proctor/Fagerberg TML value is more closely related to the Flow Table FMP than the Flow Table TML, therefore it could be considered that the use of the Proctor/Fagerberg test on IOF excludes the safety factor. In other words, the TML values from the Proctor/Fagerberg and Flow Table test are not equivalent values.

\section{Supporting Results}

This study's results can be supported by the results produced by Brazil for the International Maritime Organization [34]. Figure 26 and Table 10 shows the results produced by performing tests on IOF using all three test methods stated in the 2012 IMSBC Code.

The results show that the three tests stated in the 2012 IMSBC Code produce different TML values. The Penetration test produces the lowest TML value and the Proctor/Fagerberg produces the highest. Table 11 and Table 12 show the Proctor/Fagerberg TML value can be up to $27 \%$ greater than the Penetration TML and the Proctor/Fagerberg TML value can be up to $8 \%$ greater than the Flow Table TML.

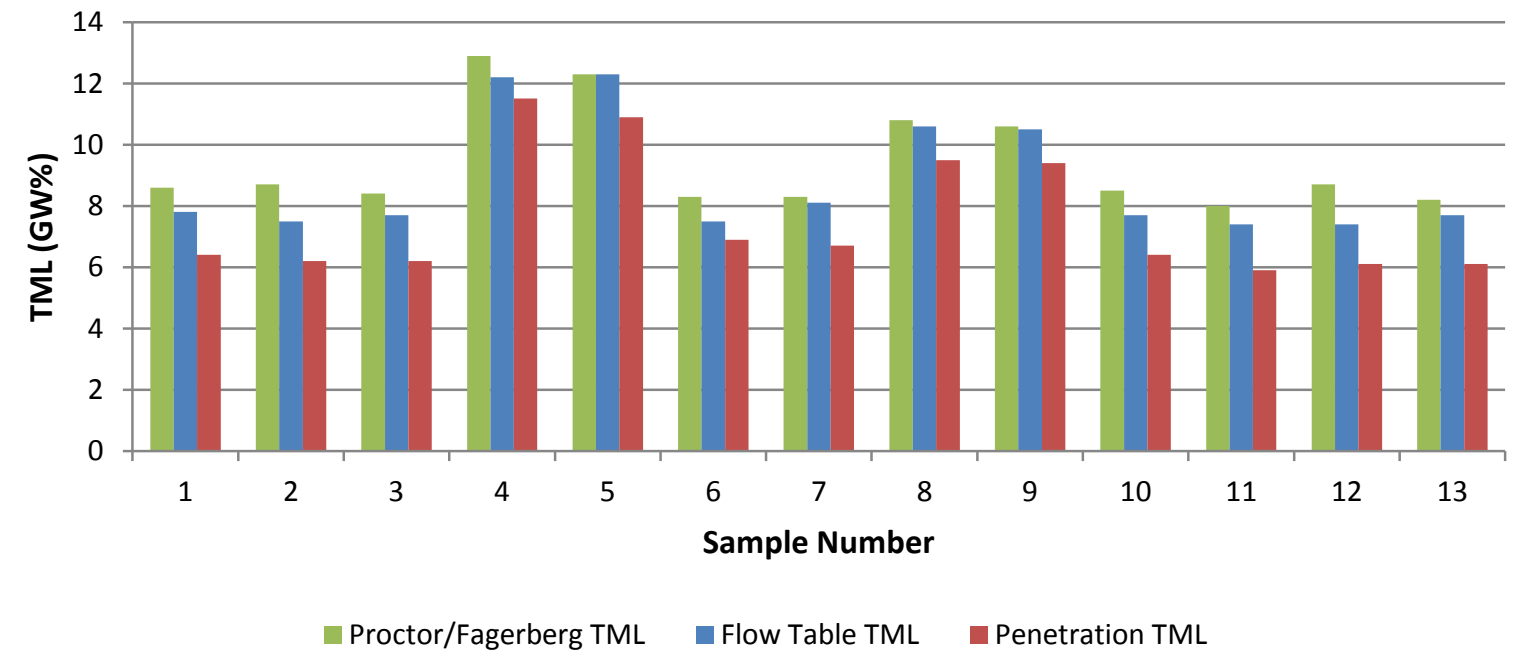

Figure 26 - Comparison by Brazil of IOF TML values using all three test methods [34].

Table 10 - Comparison by Brazil of IOF TML values using all three test methods [34].

\begin{tabular}{|l|l|l|l|}
\hline Sample & Proctor/Fagerberg TML (GW\%) & Flow Table TML (GW\%) & Penetration TML (GW\%) \\
\hline $\mathbf{1}$ & 8.6 & 7.8 & 6.4 \\
\hline $\mathbf{2}$ & 8.7 & 7.5 & 6.2 \\
\hline
\end{tabular}




\begin{tabular}{|l|l|l|l|}
\hline $\mathbf{3}$ & 8.4 & 7.7 & 6.2 \\
\hline $\mathbf{4}$ & 12.9 & 12.2 & 11.5 \\
\hline $\mathbf{5}$ & 12.3 & 12.3 & 10.9 \\
\hline $\mathbf{6}$ & 8.3 & 7.5 & 6.9 \\
\hline $\mathbf{7}$ & 8.3 & 8.1 & 6.7 \\
\hline $\mathbf{8}$ & 10.8 & 10.6 & 9.5 \\
\hline $\mathbf{9}$ & 10.6 & 10.5 & 9.4 \\
\hline $\mathbf{1 0}$ & 8.5 & 7.7 & 6.4 \\
\hline $\mathbf{1 1}$ & 8.0 & 7.4 & 5.9 \\
\hline $\mathbf{1 2}$ & 8.7 & 7.4 & 6.1 \\
\hline $\mathbf{1 3}$ & 8.2 & 7.7 & 6.1 \\
\hline
\end{tabular}

Note: The set tamper force is unknown for the Flow Table and Penetration tests as it is not stated in the report by Brazil [34].

Another representation of the data in Table 10 can be seen in Figure 27 and Table 11 and also Figure 28 and Table 12. The correlation between the Proctor/Fagerberg and Penetration tests are acceptable $\left(R^{2}=0.97\right)$, similar to the comparison between the Proctor/Fagerberg and Flow Table tests, as seen in Figure 21 (section 4.1), but the results vary from the equality line $\left(Y_{P T}=1.18 X_{P F}-3.59\right)$.

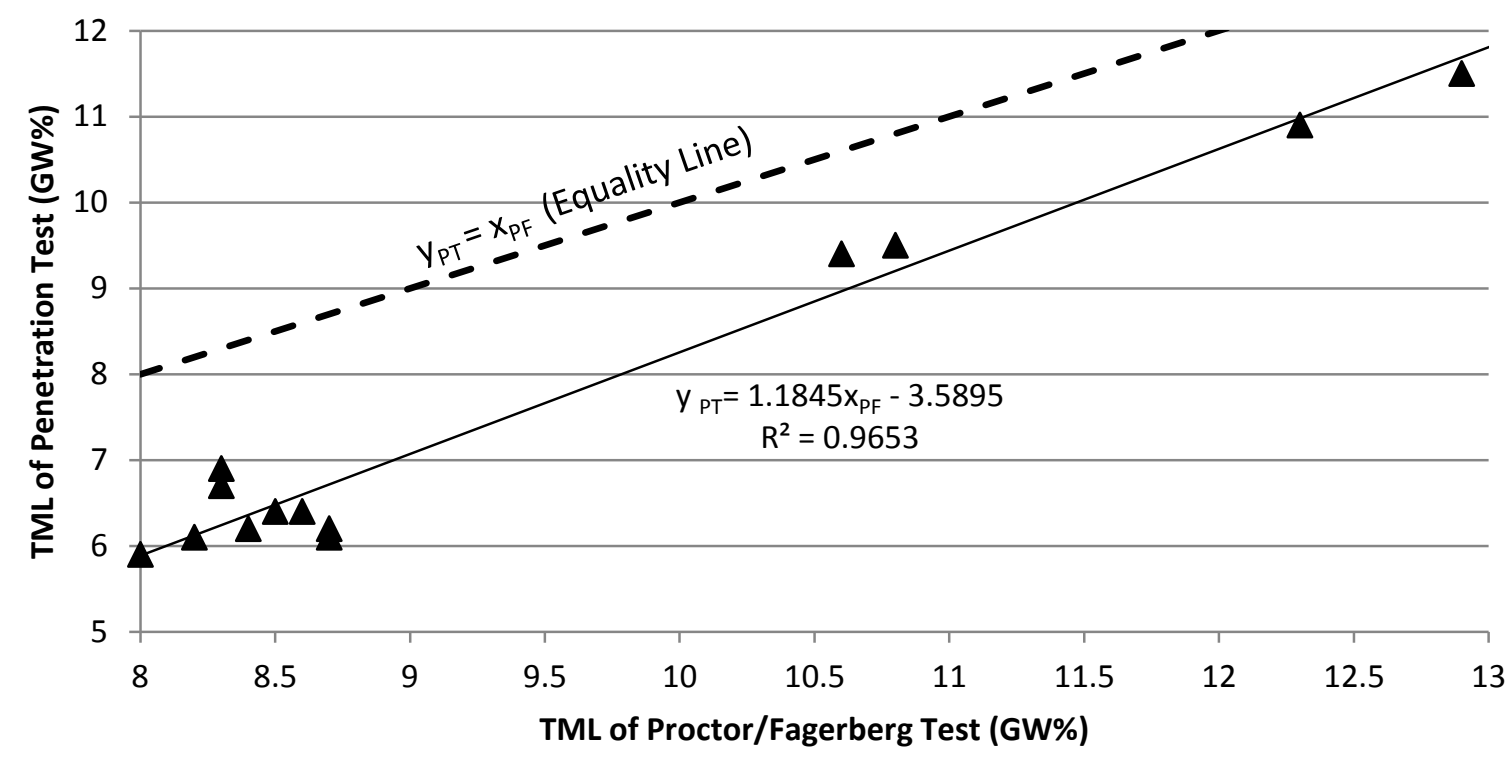

Figure 27 - Comparison by Brazil of IOF TML values using the Proctor/Fagerberg and Penetration tests [34].

Table 11 - Comparison by Brazil of IOF TML values using the Proctor/Fagerberg and Penetration tests [34].

\begin{tabular}{|l|l|l|l|l|}
\hline Sample & $\begin{array}{l}\text { TML Proctor/Fagerberg } \\
\text { (GW\%) }\end{array}$ & $\begin{array}{l}\text { Penetration TML } \\
\text { (GW\%) }\end{array}$ & $\begin{array}{l}\text { Difference between PF } \\
\text { and PT TML Values (GW\%) }\end{array}$ & $\begin{array}{l}\text { Percent Difference between } \\
\text { PF and PT TML Values (\%) }\end{array}$ \\
\hline $\mathbf{1}$ & 8.6 & 6.4 & 2.2 & 34.4 \\
\hline $\mathbf{2}$ & 8.7 & 6.2 & 2.5 & 40.3 \\
\hline $\mathbf{3}$ & 8.4 & 6.2 & 2.2 & 35.5 \\
\hline $\mathbf{4}$ & 12.9 & 11.5 & 1.4 & 12.2 \\
\hline $\mathbf{5}$ & 12.3 & 10.9 & 1.4 & 12.8 \\
\hline $\mathbf{6}$ & 8.3 & 6.9 & 1.4 & 20.3 \\
\hline $\mathbf{7}$ & 8.3 & 6.7 & 1.6 & 23.9 \\
\hline $\mathbf{8}$ & 10.8 & 9.5 & 1.3 & 13.7 \\
\hline $\mathbf{9}$ & 10.6 & 9.4 & 1.2 & 12.8 \\
\hline $\mathbf{1 0}$ & 8.5 & 6.4 & 2.1 & 32.8 \\
\hline $\mathbf{1 1}$ & 8.0 & 5.9 & 2.1 & 35.6 \\
\hline $\mathbf{1 2}$ & 8.7 & 6.1 & 2.6 & 42.6 \\
\hline $\mathbf{1 3}$ & 8.2 & 6.1 & 2.1 & 34.4 \\
\hline Average & $\mathbf{9 . 4}$ & $\mathbf{7 . 6}$ & $\mathbf{1 . 9}$ & $\mathbf{2 7 . 0}$ \\
\hline
\end{tabular}


Similar to the comparison between the Proctor/Fagerberg and Flow Table tests performed for this study, as seen in Figure 21, section 4.1, the results from the Brazilian testing show the same difference in results when comparing the Proctor/Fagerberg and Flow Table tests, as seen in Figure 28 and Table 12 [34].

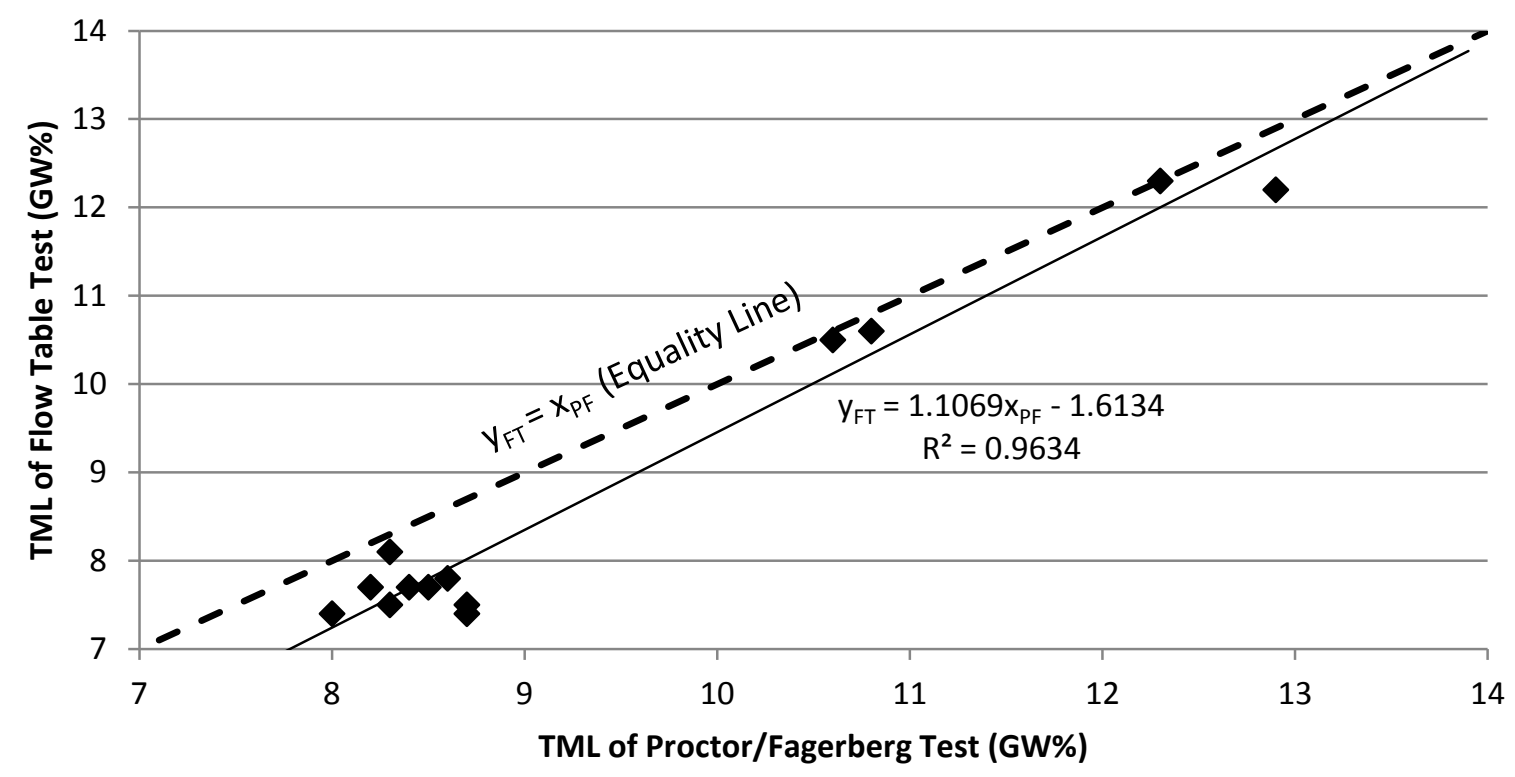

Figure 28 - Comparison by Brazil of IOF TML values using the Proctor/Fagerberg and Flow Table tests [34].

Table 12 - Comparison by Brazil of IOF TML values using the Proctor/Fagerberg and Flow Table tests [34].

\begin{tabular}{|l|l|l|l|l|}
\hline Sample & $\begin{array}{l}\text { Proctor/Fagerberg TML } \\
\text { (GW\%) }\end{array}$ & $\begin{array}{l}\text { Flow Table TML } \\
\text { (35kg.f) (GW\%) }\end{array}$ & $\begin{array}{l}\text { Difference between PF } \\
\text { and FT TML Values (GW\%) }\end{array}$ & $\begin{array}{l}\text { Percent Difference between } \\
\text { PF and FT TML Values (\%) }\end{array}$ \\
\hline $\mathbf{1}$ & 8.6 & 7.8 & 0.8 & 10.3 \\
\hline $\mathbf{2}$ & 8.7 & 7.5 & 1.2 & 16.0 \\
\hline $\mathbf{3}$ & 8.4 & 7.7 & 0.7 & 9.1 \\
\hline $\mathbf{4}$ & 12.9 & 12.2 & 0.7 & 5.7 \\
\hline $\mathbf{5}$ & 12.3 & 12.3 & 0.0 & 0.0 \\
\hline $\mathbf{6}$ & 8.3 & 7.5 & 0.8 & 10.7 \\
\hline $\mathbf{7}$ & 8.3 & 8.1 & 0.2 & 2.5 \\
\hline $\mathbf{8}$ & 10.8 & 10.6 & 0.2 & 1.9 \\
\hline $\mathbf{9}$ & 10.6 & 10.5 & 0.1 & 1.0 \\
\hline $\mathbf{1 0}$ & 8.5 & 7.7 & 0.8 & 10.4 \\
\hline $\mathbf{1 1}$ & 8.0 & 7.4 & 0.6 & 8.1 \\
\hline $\mathbf{1 2}$ & 8.7 & 7.4 & 1.3 & 17.6 \\
\hline $\mathbf{1 3}$ & 8.2 & 7.7 & 0.5 & 6.5 \\
\hline Average & $\mathbf{9 . 4}$ & $\mathbf{8 . 8}$ & $\mathbf{0 . 6}$ & $\mathbf{7 . 7}$ \\
\hline
\end{tabular}

Based on the supporting information and data obtained, depending on which test is chosen to determine the TML of IOF, the value will vary. This was proved to be true in both this study and the study produced by Brazil for the International Maritime Organization [34]. Further studies are required to determine which method gives the most reliable result when determining the TML of IOF.

\section{Discussion and Recommendations}

The preparation procedures, explained in section 2, seem unsuitable for testing materials such as IOF. One concern is with the way in which water is added to the material during preparation. Throughout the three test procedures it is necessary to add water so that the samples can be tested at different moisture contents. The maximum time that the procedures set aside for curing is five minutes. From the samples of IOF tested for this study, they contained an average of $20 \%$ fine material $(<75 \mu \mathrm{m})$. This amount of fines within a sample requires additional time to cure when compared with a uniformly graded ore concentrates, which commonly have particles $100 \mu \mathrm{m}$ to $1 \mathrm{~mm}$ in size. When 
performing the Flow Table test on samples that have not been cured long enough, the sample will break apart at the joins between the compacted layers. Uneven moisture distribution reduces the accuracy and repeatability of the tests, especially the Flow Table test where operator interpretation is essential. Additionally, at low moisture contents, constant mixing of IOF may cause segregation to occur and therefore also reduce the accuracy and repeatability of the tests.

It is recommended that the preparation procedures are modified to state that when testing is performed on fine grained materials that the sample must be left to soak for a minimum of 12 hours. The preparation of samples in polythene bags and adding increments of water to each bag, will eliminate the need to change the sample's moisture content multiple times during a test and will also eliminate the need for constant mixing. For this study, a modified preparation procedure similar to this was used.

The Penetration test states that during the preliminary test, once the FMP has been approximately determined, the material is removed from the mould, mixed back into the subsample and moisture content determined. The entire sample that was inside the mould, when the test was performed, should be used to determine the moisture content and not mixed back into the original sample prior to determining the moisture content. This is because the material in the mould and the original sample will have slightly different moisture contents by the time the test is completed.

The procedure to determine the TML, according to the Proctor/Fagerberg test, begins by drying out the material, at approximately $100^{\circ} \mathrm{C}$. This step seems unnecessary as the moisture content of the sample, when received, is likely to be drier than the TML. Drying then adding moisture back into the sample will also produce an unevenly distributed moisture content, especially if there is not enough time to allow the sample to cure before compaction of the sample.

There are numerous times when the procedure uses uncommon techniques to perform common tasks that are widely used in soil mechanics and testing. A review of these procedures is needed to determine an appropriate technique for the testing of IOF and other similar materials if they are to be performed at geotechnical and soil laboratories. Additionally, the terminology used in the 2012 IMSBC Code is at times confusing and depending on the operator's background it can determine how the code will be interpreted. Emphasis must be made regarding that the TML should be reported in gross water content not moisture content and the terminology should be standardized across all three test procedures. See Appendix A for more information on the terminology used in the 2012 IMSBC Code [2].

Currently the TML testing being performed at laboratories around Australia seem to favour the Proctor/Fagerberg test. This can be attributed to the perception that the procedure is uncomplicated and can be easily performed. This can be misleading because the determination of the particle density is rarely taken into account. The particle density of the IOF tested during this study varied from $3.8-4.8 \mathrm{t} / \mathrm{m}^{3}$ unlike the particle density of ore concentrates that can be predictable and comparatively constant, which means determining the specific gravity of IOF becomes a critical parameter.

Determining the TML by the use of the Flow Table test has its advantages and disadvantages. The main disadvantage is that the operator must be well trained to identify when the material has reached the FMP as it can sometimes be difficult when the martial has significant amounts of coarse particles, such as in IOF. The 2012 IMSBC Code's description of plastic deformation is vague and does not give the operator any in-depth detail of what to be monitoring to detect plastic deformation of IOF. An advantage of the Flow Table test is being able to determine if a material is unable to show plastic deformation as this could indicate that the material is non-liquefiable. Additionally, the Flow Table test does not involve having to perform any additional testing such as particle density.

To determine the pressure used for compaction of the sample in the Flow Table and Penetration tests, either the equation or table in the 2012 IMSBC Code is used, seen is section 2.2.6. This method seems to assume a uniform density from the top to the bottom of a cargo. Also, using the bulk density in the equation for the tamping pressure does not seem to represent the actual density at the base of the vessel, where liquefaction is most likely to occur.

On the other hand, the Proctor/Fagerberg test uses a fixed energy input from the compaction hammer. This energy is based off in situ density tests of ore concentrates, to a depth of $8 \mathrm{~m}$, and needs to be reviewed if it is to be used for the testing of IOF. This is due to the difference in densities of the materials and the depth of the cargoes. 
Additionally, when reviewing the theory behind selecting the TML from $70 \%$ saturation, it seems that it was based off studies completed in 1971 using ore concentrates and not IOF.

The maximum particle size of the sample of IOF should determine which of the three tests are to be used. The particle size distribution of IOF varies significantly from place to place, which means some samples may be able to be tested using one method where another may not. Further studies need to be completed to determine the limitations of the three test methods regarding the maximum particle size and if performing the tests on samples with particles exceeding the maximum produces a different TML.

\section{Conclusion}

A thorough literature review, along with laboratory research, was carried out to compare the TML results from the three leading test methods to determine whether they produce reliable results when testing Iron Ore Fines (IOF).

This study has shown that the results produced by the Flow Table, Proctor/Fagerberg and Penetration test methods, stated in the 2012 International Maritime Solid Bulk Cargoes Code, vary when determining the TML of IOF. If performing the Proctor/Fagerberg test on IOF the TML can be as much as 3\% greater than if the Penetration test was used. That is a $43 \%$ increase from the Penetration test to the Proctor/Fagerberg test.

It has also been found that the original materials intended for testing have significant differences in their physical properties when compared with IOF and currently no thorough study has been completed to determine which of the three test methods, if any, produce an accurate result when testing IOF.

After determining the particle size distributions of samples of IOF it was found that some samples may have more potential to liquefy than others. The physical properties that could make IOF potentially liquefiable must be studied in more detail to determine the limitations of the test procedures.

Although the three test methods produce different results, the Proctor/Fagerberg and the Flow Table tests have the potential to be modified to create a test reliable when testing IOF. Further studies are required to determine the liquefaction potential of IOF.

During this study, it was found that following the methods recommended by the 2012 International Maritime Solid Bulk Cargoes Code are not adequate for the testing IOF. An acceptable, properly instrumented physical model is needed to examine, in controlled laboratory conditions, which method is more accurate for determining the TML of IOF. Research on the physical properties of IOF, that determine the liquefaction potential, also needs to be studied and compared with the results of the physical model and the three test methods.

\section{References}

1. International Maritime Organisation, Code of Safe Practice for Solid Bulk Cargoes. 1998, London: International Maritime Organization.

2. International Maritime Organisation, International Maritime Solid Bulk Cargoes Code. 2012, London: International Maritime Organization.

3. United States Geological Survey (USGS). Iron Ore - Statistics and Information. 14/04/2012]; Available from: http://minerals.usgs.gov/minerals/pubs/commodity/iron ore/.

4. $\quad$ Fact Sheet: Iron Ore. Polinares - EU Policy on Natural Resources, Working Paper No. 41, 2012.

5. Blas, J., Iron Ore Pricing Emerges from the Stone Age, in Financial Times. 2009.

6. Kogel, J., N. Trivedi, and J. Barker, Industrial Minerals and Rocks: Commodities, Markets, and Users. Society for Mining, Metallurgy and Exploration, Inc. 7th Edition., 2006.

7. Blas, J., C. O'Murchu, and S. Bernard, Iron Ore Pricing War, in Financial Times. 2009.

8. Centre for Tankship Excellence. [cited 2013; Available from: http://www.c4tx.org/.

9. Marine Casualty Information (2011-2013). 2013 [cited 2013; Available from: http://substandard.sub.jp/kainan3.htm.

10. Bulk carrier Anna Bo listed due to cargo of iron ore shift. 2013 [cited 2013; Available from: http://www.news.odin.tc/index.php?page=view/article/1049/Bulk-carrier-Anna-Bo-listed-due-to-cargo-ofiron-ore-shift-Philippine-sea. 
11. International Maritime Organization - Intercargo, Bulk Carrier Casualty Report (1997-2006). 2007.

12. Roberts, N., Liquefaction and Bulk Carrier Total Losses: Key Issues. 2012, Joint Hull Committee.

13. Cargo ship off Mangalore, India. 2009 [cited 2013; Available from: http://www.ship.gr/news6/asianforrest.htm.

14. Searching for Missing Crew - Black Rose. 2009 [cited 2013; Available from: http://kalingadivers.com/index.php?page $=4$.

15. Sandvik, K. and A. Rein, Safe Transport at Sea of Bulk Mineral Cargoes. Bulk Solids Handling, 1992. 12(5): p. 79-83.

16. Laudal, A. The New IMSBC Code - The International Maritime Solid Bulk Cargoes Code. 2010 [cited 2013; Available

from: http://www.dnv.com.au/industry/maritime/publicationsanddownloads/publications/updates/bulk/2010/1 2010/ThenewIMSBCCodeThelnternationalMaritimeSolidBulkCargoesCode.asp.

17. Gossett, T. All about the IMSBC Code. 2012 [cited 2013; Available from: http://www.amnautical.com/blogs/news/6220592-all-about-the-imsbc-code.

18. International Maritime Organisation, Carriage of Iron ore Fines that May Liquefy (DSC.1/Circ66). 2011, International Maritime Organisation: London.

19. Kruszewski, A., When Cargoes Start to Flow. Hazardous Cargo Bulletin, 1989: p. 40.

20. International Maritime Organization, Development of New Criteria in Respect of Liquefaction and Sliding Failure - Drainage Method for Determination of the Transportable Moisture Limit (BC 26/5/14). 1984.

21. Hazen, A., Hydraulic Fill Dams. Transactions of the American Society of Civil Engineers, 1920(83): p. 17171745.

22. Davies, M., E. McRoberts, and T. Martin, Static Liquefaction of Tailings - Fundamentals and Case Histories. AMEC Earth \& Environmental, 2002.

23. Bishop, A.W. and G. Eldin, Undrained Triaxial Tests on Saturated Soils and their Significance in the General Theory of Shear Strength. Geotechnique, 1950. 2: p. 13-32.

24. Bishop, A.W., The Principle of Effective Stress. Teknisk Ukeblad, 1959. 106 (39): p. 859-863.

25. Crouch, N. and K. Aamlid. 660 - 10/09 - Iron Ore Fines Loading Issues - India. 16/10/2009 [cited 2013; Available from: http://www.ukpandi.com/loss-prevention/article/660-10-09-iron-ore-fines-loading-issuesindia-925/.

26. Fagerberg, B., Determination of Critical Moisture Contents in Ore Concentrates Carried in Cargo Vessels. Minerals Transportation, 1971: p. 174-191.

27. American Society for Testing and Materials, ASTM Designation D698 - Standard Test Methods for Laboratory Compaction Characteristics of Soil Using Standard Effort. 2012.

28. American Society for Testing and Materials, ASTM Designation C230 / C230M - Standard Specification for Flow Table for Use in Tests of Hydraulic Cement. 2008.

29. American Society for Testing and Materials, ASTM Designation C124 - Method of Test for Flow of PortlandCement Concrete by use of the Flow Table. 1971.

30. American Society for Testing and Materials. ASTM Designation C230 - Standard Specification for Flow Table for Use in Tests of Hydraulic Cement. 1952 [cited 2013; Available from: http://www.standardscatalog.com/catalog/show/ASTM-C230/history/.

31. International Standards Organization, ISO 12742 - Copper, Lead, and Zinc Sulfide Concentrates Determination of Transportable Moisture Limits - Flow-Table Method. 2007.

32. Japanese Standards Association, JIS A 1210 - Test Method for Soil Compaction Using a Rammer. 2009.

33. Tanaka, M. and T. Ura, Development of The Penetration Method for Mineral Concentrates. International Maritime Organization, Sub-Committee on Dangerous Goods, Solid Cargoes and Containers, BC 30/5/12, 1989.

34. International Maritime Organisation. Inadequacy of Current IMSBC Code Methodologies to Transportable Moisture Limit Determination on Brazilian Iron Ore Fines, 17th Session, Agenda Item 4, DSC 17/INF.10. in Sub-Committee on Dangerous Goods, Solid Cargoes and Containers. 2012.

35. Ura, T., Determination of Transportable Moisture Limit of Bulk Cargoes, in Proc. of TDG 11. 1992: Institute of Industrial Science, University of Tokyo.

36. Standards Australia, AS 1289.0-2000 - Method of Testing Soils for Engineering Purposes. 2000.

37. Ishihara, K., Stability of Natural Deposits during Earthquakes, in 11th International Conference on Soil Mechanics and Foundation Engineering. 1985: San Francisco. p. 321-376.

38. International Standards Organization, ISO 3087 - Iron Ores - Determination of Moisture Content of a Lot. 1998. 
39. International Standards Organization, ISO 589 - Hard Coal - Determination of Total Moisture. 2008. 


\section{Appendix A - Terminology}

The terminology used in the 2012 IMSBC Code [2], when referring to the three test methods, can be at times misleading depending on the background of the operator. Due to this, people familiar with the common terms used in soil mechanics and geotechnical engineering, and not standard testing of metallurgy or materials such as IOF, can be misled to make critical errors in calculations and reporting the results. A common guide used by metallurgists where gross water content is determined can be seen in ISO 3087 - Determination of Moisture Content of a Lot [38].

In soil mechanics and geotechnical engineering, the term 'moisture content' refers to the ratio of the mass of moisture to the mass of the solid material, as seen in eq. A.1.

Moisture Content (MC\%) = Mass of Water $/$ Mass of Solids $\times 100$

In the Flow Table and Penetration test procedures the IMSBC Code (2012, app. 2, para. 1.1.4.4.1-2) refers to 'moisture content' as the percent of moisture when compared to the total sample, which is the total mass of the sample including moisture [2]. In soil mechanics and geotechnical engineering this is referred to as the 'gross water content', as seen in eq. A.2.

Gross Water Content $($ GW\% $)=$ Mass of Water $/$ Total Mass $x 100$

Other terms that were found to cause confusion in the 2012 IMSBC Code are terms such as 'dry bulk density', which should read 'dry density', as dry density and bulk density are different physical properties. Also, 'density of solid material' should read 'particle density' or 'specific gravity', in the Flow Table test, and 'top size' should read 'maximum particle size', in the Penetration test. Furthermore, some terms have different definitions when looking at the three tests independently, such as the following:

"Flow Moisture Point" (FMP):

In the Flow Table test the FMP is the gross water content at which the material is verging on plastic deformation. In the Penetration test it is the gross water content at which the depth of Penetration from the bit is $50 \mathrm{~mm}$. In the Proctor/Fagerberg test it is inferred as the 'Critical Moisture Content' or 'TML'.

"Critical Moisture Content" (CMC):

In the Flow Table and Penetration test there is no reference to the CMC but is assumed to be equal to the 'Flow Moisture Point'. In the Proctor/Fagerberg test it is the gross water content at which the compaction curve crosses the $70 \%$ saturation line in the graphical representation and equal also equal to the 'TML'.

"Transportable Moisture Limit" (TML):

In the Flow Table and Penetration tests the TML is $90 \%$ of the 'Flow Moisture Point'. In the Proctor/Fagerberg test it is also referred to as the 'Critical Moisture Content' and is equal to the gross water content at which the compaction curve crosses the $70 \%$ saturation line, in the graphical representation. The TML is the maximum gross water content that bulk cargoes may contain while being transported in bulk carriers without being at risk of liquefying.

"Flow State":

In the Flow Table test it is referred to when the material is showing plastic deformation. In the Penetration test it is referred to when the material can be penetrated by the bit to a depth greater than $50 \mathrm{~mm}$. This is when the material has a gross water content greater than the FMP. 


\section{Appendix B - Calculations}

\section{B.1 Proctor/Fagerberg Test Calculations}

Using the equations given in the 2012 IMSBC Code [2] can produce improper results. The moisture content and bulk density determinations should be calculated separately unless the sample is dried inside the mould, which is impractical. This is because when the material is removed from the mould there is always going to be some material left behind meaning that the dry mass removed is not the dry mass in the mould. Furthermore, the volume of the mould is never exactly $1000 \mathrm{~cm}^{3}$. The volume of the mould should be measured accurately prior to testing and used in place of $1000 \mathrm{~cm}^{3}$. During this study eq. B.1 to eq. B.7 were used to determine the TML of IOF when performing the Proctor/Fagerberg test and to create the final graphical representations of the compaction curves:

The bulk density $(\rho)$, in $t / \mathrm{m}^{3}$, of each compacted specimen is:

$\rho=\left(m_{2}-m_{1}\right) / V$

Where $\quad m_{1} \quad$ is mass of mould and base plate (in g); and

$\mathrm{m}_{2} \quad$ is mass of mould, base plate and compacted soil (in g); and

$\checkmark \quad$ is internal volume of the mould (in $\mathrm{cm}^{3}$ ); and

$\rho \quad$ is the bulk density of each compacted specimen (in $t / \mathrm{m}^{3}$ ).

The dry density $\left(\rho_{d}\right)$, in $t / \mathrm{m}^{3}$, of each compacted specimen is:

$\rho_{d}=100 \rho /(100+w)$

Where w is the moisture content of the soil (in \%); and

$\rho \quad$ is the bulk density of each compacted specimen (in $\mathrm{t} / \mathrm{m}^{3}$ ); and

$\rho_{d} \quad$ is the dry density of each compacted specimen (in $t / \mathrm{m}^{3}$ ).

The void ratio (e) of each compacted specimen is:

$e=\left(\rho_{s t}-\rho_{d}\right) / \rho_{d}$

Where $\quad \rho_{\mathrm{st}} \quad$ is the particle density of the total soil sample (in $\mathrm{t} / \mathrm{m}^{3}$ ); and

$\rho_{\mathrm{d}} \quad$ is the dry density of each compacted specimen (in $\mathrm{t} / \mathrm{m}^{3}$ ); and

e is the void ratio of each compacted specimen.

The gross water content ( $\left.w_{\text {gross }}\right)$, in $\%$, of each compacted specimen is:

$\mathrm{w}_{\text {gross }}=100-(100 /(1+\mathrm{w} / 100))=$ Mass of Water $/$ Total Mass $\times 100$

Where $\quad$ w is the moisture content of the soil (in \%); and

$\mathrm{w}_{\text {gross }}$ is the gross water content (in \%).

The void ratio $(e)$ at different gross water contents $\left(w_{\text {gross }}\right)$, in \%, for corresponding degrees of saturation $(S)$, in \%, is:

$e=\rho_{\text {st }} \times\left(w_{\text {gross }} \times 100 /\left(100-w_{\text {gross }}\right)\right) / S$

Where $\quad \rho_{\text {st }} \quad$ is the particle density of the total soil sample (in $\left.t / \mathrm{m}^{3}\right)$; and

$\mathrm{S} \quad$ is the degree of saturation (in \%); and

$\mathrm{w}_{\text {gross }}$ is the gross water content (in \%); and

e is the void ratio of each compacted specimen. 


\section{B.2 Flow Table and Penetration Test Calculations}

Equations given in the 2012 IMSBC Code [2] are those described in ISO 589- Hard Coal - Determination of Total Moisture [39]. These are used when performing the Flow Table and Penetration tests.

Gross water content, in percent, of material "as received" is:

$\mathrm{w}_{\text {gross }}=\left(m_{3}-m_{4}\right) / m_{3} \times 100$

Where $\quad m_{3} \quad$ is mass of subsample "as received"

$\mathrm{m}_{4} \quad$ is mass of subsample "as received", after drying

The FMP, in percent, of the material is:

$\mathrm{FMP}=\left(\left(m_{5}-m_{6}\right) / m_{5}+\left(m_{7}-m_{8}\right) / m_{7}\right) / 2 \times 100$

Where $\quad m_{5} \quad$ is mass of sample just above flow state

$m_{6} \quad$ is mass of sample just above flow state, after drying

$\mathrm{m}_{7} \quad$ is mass of sample just below flow state,

$m_{8} \quad$ is mass of sample just below flow state, after drying

The TML of the material is $90 \%$ of the FMP. 


\section{Appendix C - Typical TML Results}

Additional TML values and other final test properties of IOF obtained from further testing during this study and the results reported by Brazil [34] are shown in Table C.1 to Table C.3. These were obtained by using the three test methods stated in the 2012 IMSBC Code [2].

Table C.1 - Typical IOF Proctor/Fagerberg TML test results from this study.

\begin{tabular}{|l|l|l|l|}
\hline & Minimum & Maximum & Average \\
\hline TML (GW\%) & 8.00 & 16.80 & 11.03 \\
\hline Maximum Dry Density from Proctor/Fagerberg $\mathbf{( t / \mathbf { m } ^ { \mathbf { 3 } } )}$ & 2.05 & 2.95 & 2.55 \\
\hline Void Ratio at Maximum Dry Density & 0.50 & 1.06 & 0.67 \\
\hline Dry Density from Proctor/Fagerberg at 70\% Saturation $\mathbf{( t / \mathbf { m } ^ { \mathbf { 3 } } \mathbf { ) }}$ & 1.91 & 2.80 & 2.40 \\
\hline Void Ratio at 70\% Saturation & 0.57 & 1.24 & 0.77 \\
\hline
\end{tabular}

Table C.2 - Typical IOF Flow Table TML test results from this study.

\begin{tabular}{|l|l|l|l|}
\hline & Minimum & Maximum & Average \\
\hline Flow Moisture Point (GW\%) & 8.22 & 13.67 & 10.48 \\
\hline TML (GW\%) & 7.40 & 12.30 & 9.43 \\
\hline Maximum Dry Density from Flow Table using 35kg.f (t// $\mathbf{m}^{\mathbf{3}}$ ) & 2.48 & 2.84 & 2.64 \\
\hline
\end{tabular}

Table C.3 - Typical IOF Penetration TML test results from Brazil [34].

\begin{tabular}{|l|l|l|l|}
\hline & Minimum & Maximum & Average \\
\hline TML (GW\%) & 5.90 & 11.50 & 7.55 \\
\hline
\end{tabular}

